\title{
DETERMINATION OF THE MODAL PARAMETERS OF A FIVE STORY REINFORCED CONCRETE STRUCTURE USING ULTRA-LOW LEVEL EXCITATION AND COMPUTATIONAL ANALYSIS
}

\author{
A Thesis \\ Presented to \\ the Faculty of California Polytechnic State University \\ San Luis Obispo
}

In Partial Fulfillment

Of the Requirements for the Degree

Master of Science in Architecture with a Specialization in Architectural Engineering

by

Adam Russell Rendon

Fall 2011 
(C) 2011

Adam Russell Rendon

ALL RIGHTS RESERVED 
COMMITTEE MEMBERSHIP

TITLE: $\quad$ Determination of the Modal Parameters of a Five Story Reinforced Concrete Structure Using Ultra-Low Level Excitation and Computational Analysis

AUTHOR: $\quad$ Adam Russell Rendon

DATE SUBMITTED: $\quad$ Fall 2011

COMMITTE CHAIR: $\quad$ Cole McDaniel, Ph.D.

COMMITTEE MEMBER: Graham Archer, Ph.D.

COMMITTEE MEMBER: Abe Lynn, Ph.D. 


\begin{abstract}
Determination of the Modal Parameters of a Five Story Reinforced Concrete Structure Using Ultra-Low Level Excitation and Computational Analysis
\end{abstract}

Adam Russell Rendon

The determination of a building's modal parameters (natural periods and mode shapes) using ultra-low level forced vibration testing and analytical modeling were critically compared. The structure utilized for this experiment is the Robert E. Kennedy Library on the campus of California Polytechnic State University San Luis Obispo, a five-story reinforced concrete shear wall structure. The specific testing procedure used has been verified to produce accurate results in smaller buildings, but the Kennedy Library represents the most massive subject structure. Other characteristics of this structure that make it unique include a large atrium at the center of the building and modes that are closely spaced in the frequency domain. Comparing the results from the computational models and the experimental analysis showed that the computational models underestimated the building periods by approximately $6-12 \%$. This discrepancy in the results was attributed to an underestimation of the building mass, possible soilstructure interaction, and likely cracking of the concrete slab and shear walls. Modeling of the shear walls as both line elements and area elements was also explored and the consequences of each were determined. 


\section{Table of Contents}

List of Figures .................................................................................................... vi

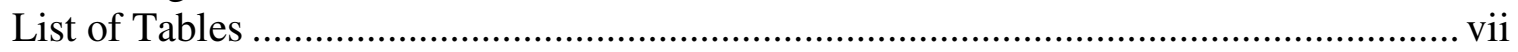

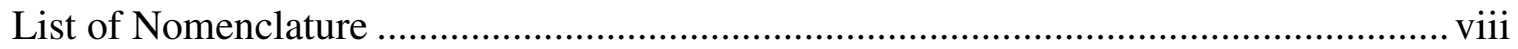

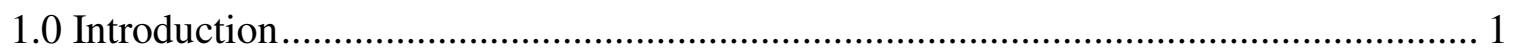

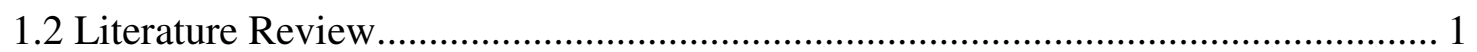

1.3 Structural Basis ............................................................................................. 4

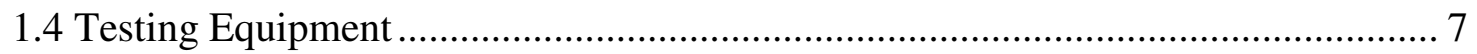

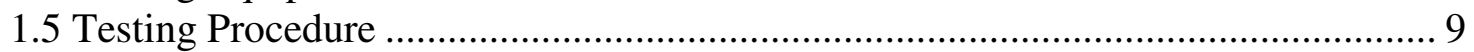

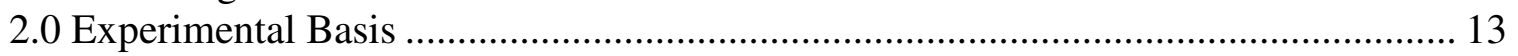

2.1 Theoretical Validation of the Experimental Readings ......................................... 13

2.2 Ambient Vibration Testing .............................................................................. 19

2.3 Experimental Determination of Apparent Mode Shape 1.................................. 21

2.4 Experimental Determination of Apparent Mode Shape 2 ................................... 27

2.5 Experimental Determination of Apparent Mode Shape 3.................................... 29

2.6 Floor-to-Floor Variation of Apparent Mode Shapes 1, 2 and 3............................ 32

2.7 Modal Orthogonality of the Apparent Mode Shapes ........................................... 34

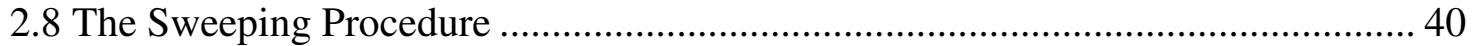

2.9 Experimental Conclusions .............................................................................. 42

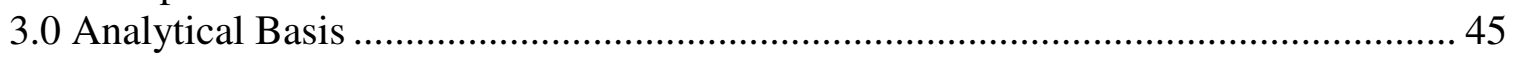

3.1 Progression of Analytical Modeling ............................................................... 45

3.2 Comparison of Analytical to Experimental Mode Shapes................................... 62

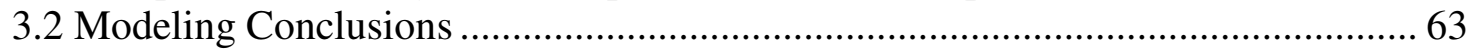

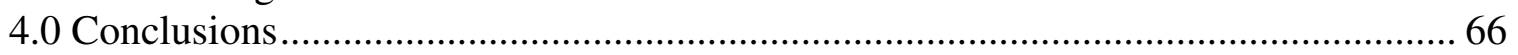

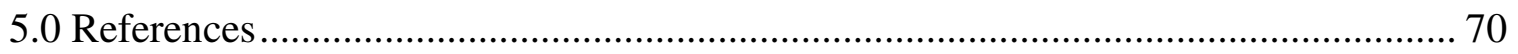




\section{List of Figures}

Figure A: Robert E. Kennedy Library …………………….................................... 5

Figure B: Aerial View of the Kennedy Library …………….................................... 5

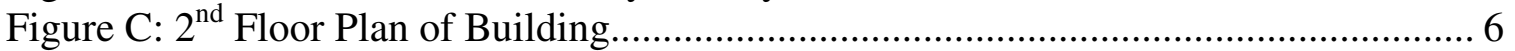

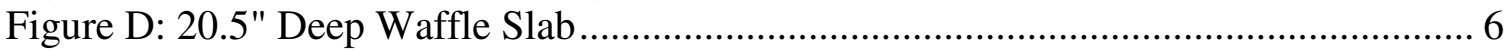

Figure E: Typical Arrangement of Furniture ............................................................ 7

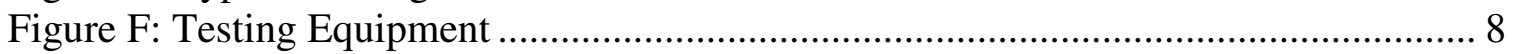

Figure G: Accelerometer Orientation ....................................................................... 9

Figure H: Half Period of Accelerometer Time Histories................................................ 12

Figure I: Relative Acceleration Directions ........................................................... 12

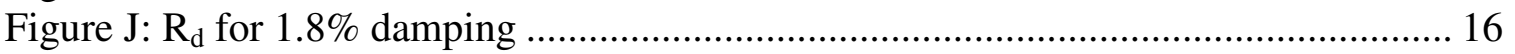

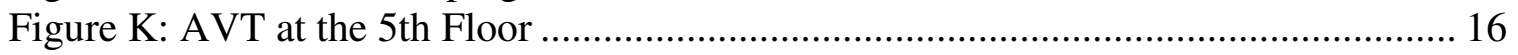

Figure L: Ambient Vibration vs. Forced Vibration …………...................................... 17

Figure M: Computational Set-up ................................................................................. 18

Figure N: Location of Accelerometers for Ambient Reading ………........................... 20

Figure O: Ambient Vibration FFT Response.............................................................. 20

Figure P: Shaker and Accelerometer Location ............................................................ 22

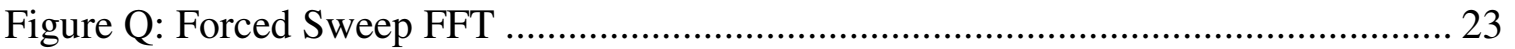

Figure R: Relative Acceleration Values …………………..................................... 24

Figure S: Shaker and Accelerometer Location ............................................................. 25

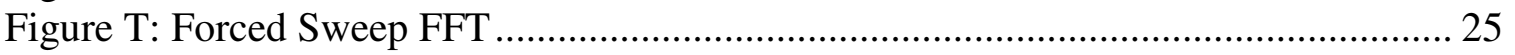

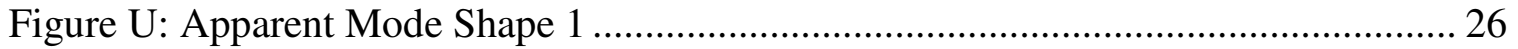

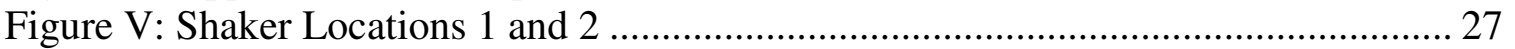

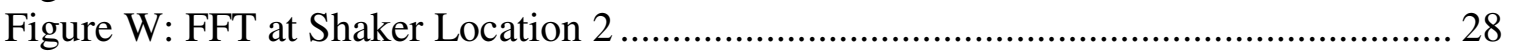

Figure X: Apparent Mode Shape 2 ……………………................................. 28

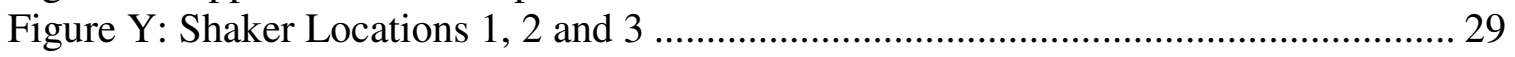

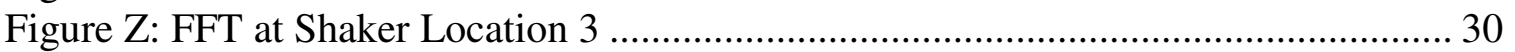

Figure AA: Flexibility in Apparent Mode Shape 3 ................................................. 31

Figure BB: Flexibility in Apparent Mode Shape 3 ……........................................... 32

Figure CC: Apparent Mode Shape 3 ........................................................................... 32

Figure DD: Vertical Variation of Accelerations for AMS 1 at N-E Corner of Library.... 33

Figure EE: Modal Analysis at Shaker Location 3 …………....................................... 38

Figure FF: Shaker Locations for Further Investigation .................................................. 39

Figure GG: Apparent Mode Shape 1 vs. Experimental Mode Shape 1 .......................... 42

Figure HH: Apparent Mode Shape 3 vs. Experimental Mode Shape 3 ............................ 42

Figure II: Lumped Mass Model ................................................................................ 46

Figure JJ: Modeling Walls as Line Elements ................................................................ 47

Figure KK: Compatibility Error at Wall/Slab Intersection............................................... 48

Figure LL: Rigid Constraints at Wall/Slab Intersection .................................................. 49

Figure MM: Test Wall for Torsional Stiffness ............................................................. 50

Figure NN: Rigid Diaphragm Constraints at Wall/Slab Intersection .............................. 52

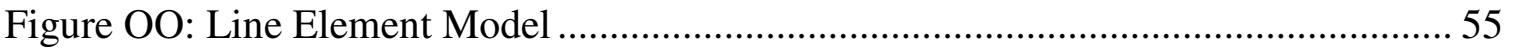

Figure PP: Meshed Wall Model................................................................................. 58 


\section{List of Tables}

Table 1: Experimental vs. Computational Accelerations ............................................ 19

Table 2: Mass Weighted MAC Numbers Comparing the Apparent Mode Shapes .......... 35

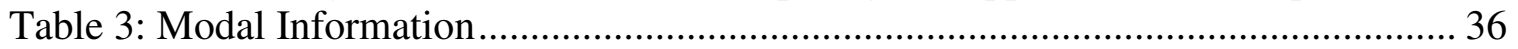

Table 4: Summary of Experimental Mode Shapes ..................................................... 41

Table 5: Comparison Between Line and Shell Element Used for Torsion....................... 50

Table 6: Mesh Density vs. Torsional Mode Period ..................................................... 54

Table 7: Line Wall Element Model vs. Experimental Results.........................................56

Table 8: Experimental Results vs. Cracked Line Wall Element Model .......................... 57

Table 9: Exp. Results vs. Cracked Line Wall Element Model (Additional 3" Concrete) 57

Table 10: Exp. Results vs. Cracked Line Wall Element Model (60\% Gross Stiffness) ... 57

Table 11: Meshed Wall Model vs. Experimental Results..............................................59

Table 12: Experimental Results vs. Cracked Meshed Wall Model ................................. 59

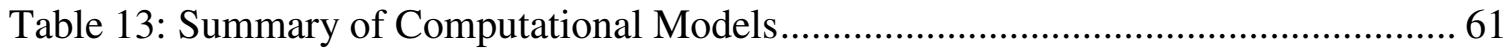

Table 14: MAC Numbers Comparing the Line Element Model Mode Shapes with the

Apparent Mode Shapes (AMS) and Experimental Mode Shapes (EMS) ......................... 62 


\section{List of Nomenclature}

AMS - Apparent Mode Shape

AVT - Ambient Vibration Test

DAQ - Data Acquisition Device

EMS - Experimental Mode Shape

EW - East-West

FVT - Forced Vibration Test

FFT - Fast Fourier Transform

g - Gravity

$\mathrm{Hz}-\operatorname{Hertz}\left(\mathrm{s}^{-1}\right)$

MAC - Mass Weighted Modal Assurance Criterion

NS - North-South

pcf - Pound Per Cubic Foot

$\mu \mathrm{g}-$ Gravity * $\left(10^{-6}\right)$ 
Introduction 1

\subsection{INTRODUCTION}

Modal parameters such as natural frequencies, mode shapes, and modal damping ratios are key information in determining the dynamic performance of a building. This information is used in a modal analysis to determine such quantities as building displacement and strength demands due to any variety of external forces. However, the accuracy of these quantities depends on the accuracy of the modal parameters used in the analysis. Since modal parameters are typically obtained from computational models, it is important that such models capture as closely as possible the stiffness and mass of the structure. One way to gain reasonable assurance that these computational models are accurate is to compare them to experimental results.

This thesis critically compares the natural frequencies and mode shapes obtained experimentally with those obtained through computational modeling.

\subsection{Literature Review}

Forced Vibration testing of buildings has been studied since the 1960's (Hudson 1961) when the first eccentric mass shakers were developed. These shakers are still used today and consist of two weights rotating about a vertical axis. They are capable of producing a harmonic load at various magnitudes in a single direction. Some are capable of putting out a force as high as 100,000 lbs. (Yu et al. 2008). However, these types of shakers are heavy and not easily relocated throughout a building. Another problem associated with these types of shakers is the difficulty in generating large forces at low amplitudes. Also, eccentric mass shakers are only capable of producing a harmonic force and therefore cannot be used to simulate ground motion.

\footnotetext{
Determination of the Modal Parameters of a Five Story Reinforced Concrete Structure Using Ultra-Low Level Excitation and Computational Analysis
} 
Introduction 2

Another type of shaker is the linear mass shaker. It generates forces through the linear motion of a moving mass. This type of shaker is not limited to a harmonic forcing function and can therefore be used to simulate seismic motion at low amplitudes. The force generated by these types of shakers can reach 15,000 lbs. (Yu et al. 2008).

In the study, "Forced Vibration Testing of a Four-Story Reinforced Concrete Building Utilizing the NEES@UCLA Mobile Field Laboratory,” (Yu et al. 2008) the authors use two large capacity eccentric mass shakers for harmonic excitation and a linear mass shaker for seismic simulation of a structure previously damaged by the 1994 Northridge earthquake. The building was densely instrumented with accelerometers and concrete strain gauges. The authors were able to identify the first seven natural frequencies, mode shapes, and modal damping values of the building. They were also able to verify the rigid diaphragm assumption and the insignificance of "soil-structurefoundation-interaction" in the linear range for this type of building. The use of strain gauges provided data that led to the determination of an effective slab thickness and also led to the ability to relate observed damage at slab-column connections to their moment transfer ability. Another important result of the experiment was that the natural frequencies of the building were found to be different based on the excitation force. For example, the data produced by the large capacity eccentric mass shakers resulted in natural frequencies that were only $70 \%$ of those obtained from ambient vibration tests, and as high as $93 \%$ of those obtained from the lower capacity linear mass shaker. The authors attributed these differences to the nonlinear effects of concrete cracking and the

\footnotetext{
Determination of the Modal Parameters of a Five Story Reinforced Concrete Structure Using Ultra-Low Level Excitation and Computational Analysis
} 
Introduction 3

presence of existing cracks. Similar shifts in frequency due to magnitude of input force are examined in, "Dynamic Characteristics of Five Tall Buildings During Strong and Low-Amplitude Motions" (Celebi et al. 1993). This paper looked at five buildings within the San Francisco Bay area that were instrumented before the 1989 Loma Prieta earthquake (LPE). The buildings represented a range of different structural systems and suffered no visible damage during the LPE. The recorded responses of the buildings to the LPE were used to derive the fundamental frequencies of the buildings. In September of 1990, ambient vibration tests were conducted on these buildings to determine the fundamental frequencies that would be used to compare to those determined from the LPE data. The authors found that the first mode period ratios (LPE/ambient) ranged from 1.14 to 1.47 . The largest ratios were observed for a reinforced concrete moment-resisting frame structure and the smallest ratios were observed for a steel moment-resisting frame structure. The authors attributed these differences to possible soil-structure interaction, non-linear behavior of the structures, slip of steel connections, concrete cracking, and the interaction of nonstructural elements. The authors concluded that low-amplitude test results should be used with caution if they are to be used to predict the dynamic characteristics of buildings during strong-motion.

This research illustrates the significance that forced vibration testing can have in the validation of design assumptions and the understanding of structural dynamics and building behavior. However, the tests performed by these researchers were performed with very large equipment and numerous measurement devices. This paper looks

\footnotetext{
Determination of the Modal Parameters of a Five Story Reinforced Concrete Structure Using Ultra-Low Level Excitation and Computational Analysis
} 
Introduction 4

specifically at Ultra-Low level Forced Vibration Testing (UL-FVT), a testing procedure that utilizes portable equipment that cannot damage buildings. More specifically, it explores the capability of UL-FVT to excite a large building to a measurable extent. These measurements are then used to extract natural periods and mode shapes.

\subsection{Structural Basis}

The building under investigation is the Robert E. Kennedy Library located on the campus of California Polytechnic State University, San Luis Obispo (see Figure A). It is a five-story reinforced concrete shear wall structure built in 1977. One of the unique characteristics of this building is the large atrium located near the center that runs the entire height of the building and takes up roughly $10-16 \%$ of the entire floor area. As will be discussed in section 2, this atrium causes some difficulties in the experimental determination of the mode shapes, such as not being able to shake at the center of mass (the atrium is illustrated in Figure B). Another unique characteristic of this building is the arrangement of shear walls. Shown in figure $C$, many of the walls have unique cross sections, and their positioning is irregular. Also, many of the walls are discontinuous; some begin on upper floors and don't run the full building height.

\footnotetext{
Determination of the Modal Parameters of a Five Story Reinforced Concrete Structure Using Ultra-Low Level Excitation and Computational Analysis
} 


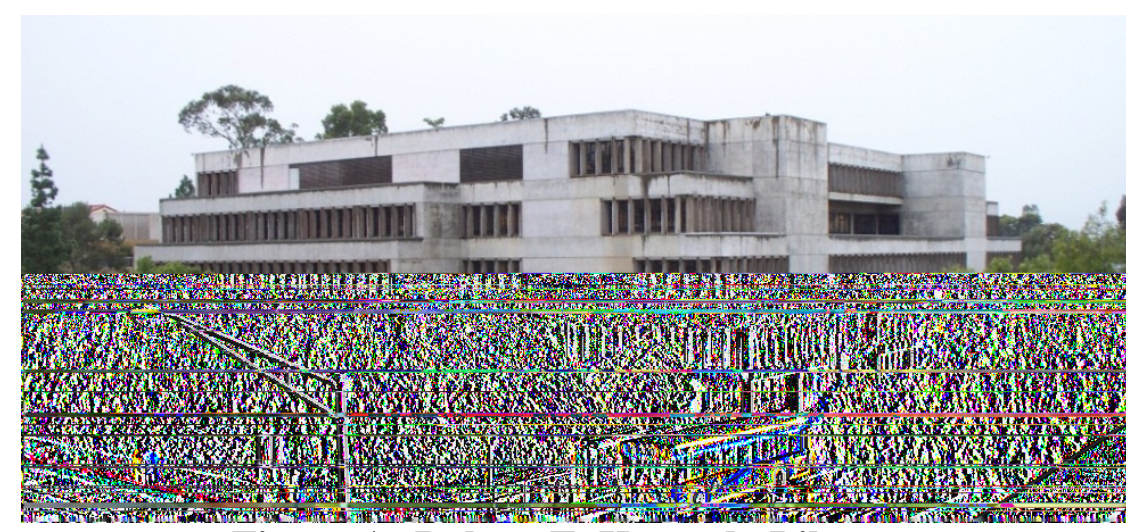

Figure A: Robert E. Kennedy Library

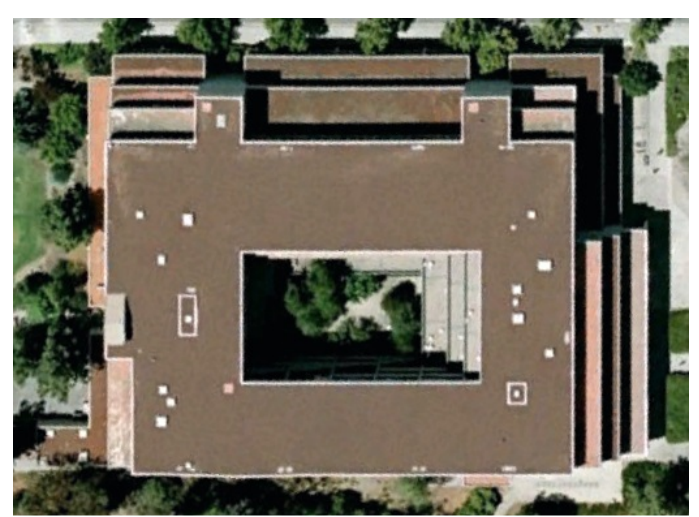

Figure B: Aerial View of the Kennedy Library

Source: Google Earth

Determination of the Modal Parameters of a Five Story Reinforced Concrete Structure Using Ultra-Low Level Excitation and Computational Analysis 


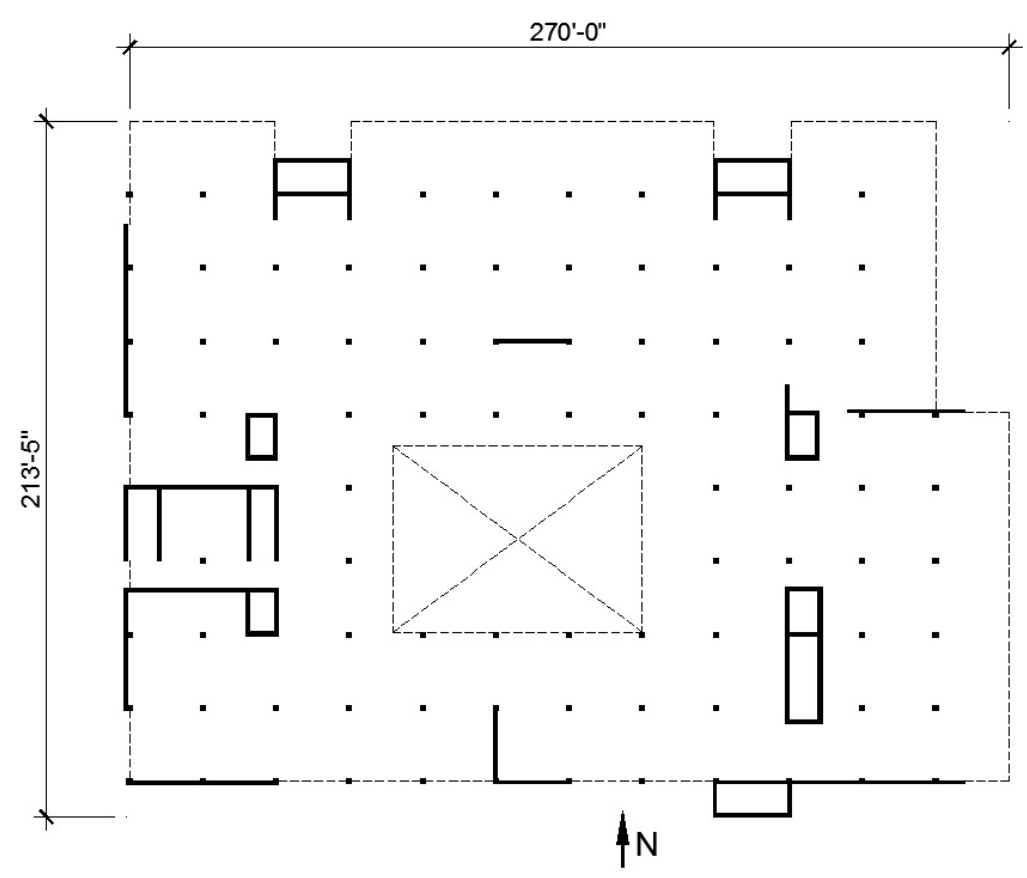

Figure C: $2^{\text {nd }}$ Floor Plan of Building

The building diaphragm consists of a 20.5" deep waffle slab (figure D); and the roof consists of concrete slab on metal deck over steel framing. The waffle slab is lightweight (110 pcf) concrete and the walls and columns are made up of normal weight concrete (150 pcf). Special consideration of the library books and furniture was necessary when estimating the mass of the structure (Figure E illustrates a typical furniture layout).

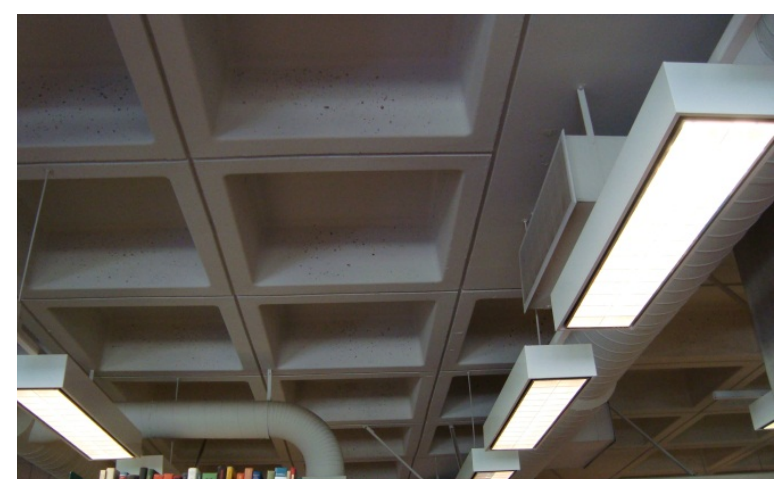

Figure D: 20.5" Deep Waffle Slab

Determination of the Modal Parameters of a Five Story Reinforced Concrete Structure Using Ultra-Low Level Excitation and Computational Analysis 


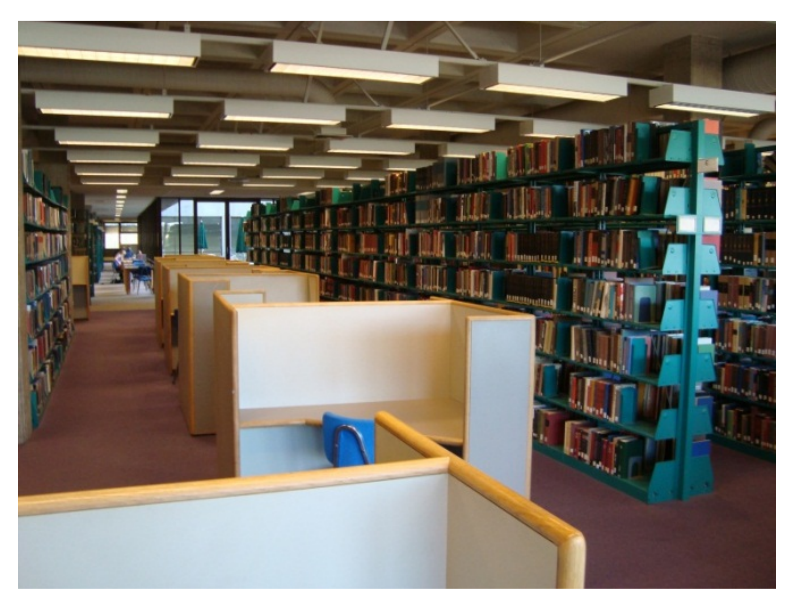

\section{Figure E: Typical Arrangement of Furniture}

\subsection{Testing Equipment}

Ultra-Low Level Forced Vibration Testing (UL-FVT) (McDaniel and Archer 2010a) is used in this project to experimentally determine the natural frequencies and mode shapes of the Kennedy Library. The equipment consists of a small linear shaker, a signal generator, an amplifier, accelerometers, a data acquisition device (DAQ), and a computer with data reduction software. The equipment is pictured in Figure F. All of the equipment is portable and can be operated by one person.

\footnotetext{
Determination of the Modal Parameters of a Five Story Reinforced Concrete Structure Using Ultra-Low Level Excitation and Computational Analysis
} 


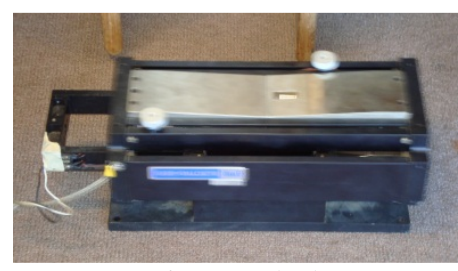

Linear Shaker

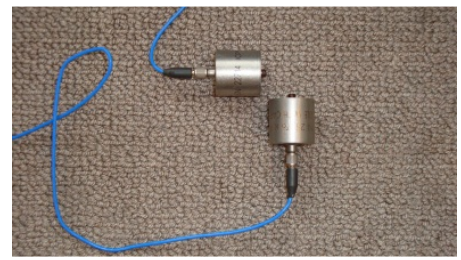

Accelerometers

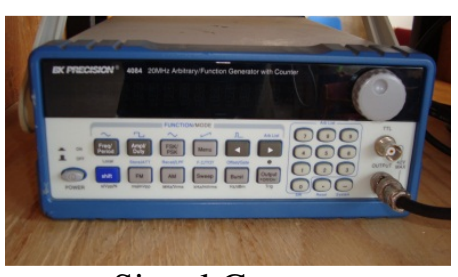

Signal Generator

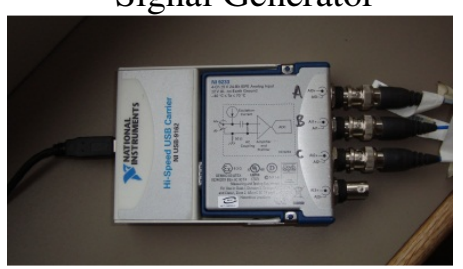

DAQ

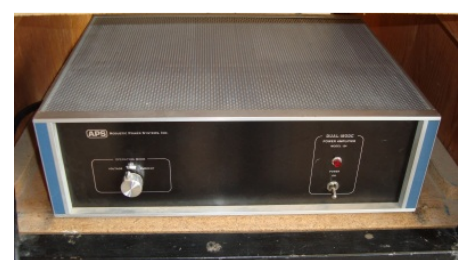

Amplifier

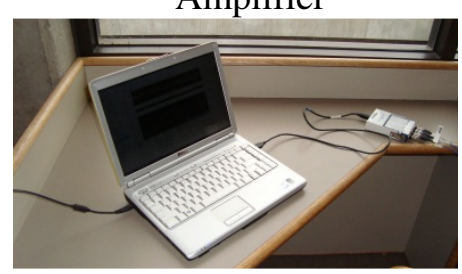

Computer

Figure F: Testing Equipment

The long-stroke linear shaker weighs about $100 \mathrm{lbs}$. and is capable of producing a consistent sinusoidal force of $30 \mathrm{lbs}$. over a frequency range of 2-20 Hz. Since the shaker produces a small force, friction at its base is sufficient to transfer the force to the structure without needing special anchorage. Designed for scale buildings, this linear shaker, when properly placed, has been proven to excite buildings under 4 floors, and under 30,000 square feet (McDaniel and Archer 2010a). The Kennedy Library is 5 floors and is 31,000 square feet at the roof, increasing to 50,000 square feet at the $2^{\text {nd }}$ floor. The total size of the building is 180,000 square feet and the total weight is roughly 20,000 tons (weight tributary to the $2^{\text {nd }}$ floor diaphragm and up).

The accelerometers used to capture the motion of the building are piezoelectric flexural accelerometers. They have a frequency range of less than $1 \mathrm{~Hz}$ to greater than $200 \mathrm{~Hz}$ and have broadband resolutions of 1-3 $\mu \mathrm{g}$ rms. Throughout the experimental testing they were arranged as shown in figure G. To determine the rotation, accelerometer

Determination of the Modal Parameters of a Five Story Reinforced Concrete Structure Using Ultra-Low Level Excitation and Computational Analysis 
Introduction 9

B was set $16^{\prime}$ away from accelerometer $A$ and the rotation was determined from the

following equation

$$
\frac{A-B}{x} \times g
$$

Where $A$ and $B$ are the accelerations from the two accelerometers $(\mathrm{g})$,

$g$ is the acceleration due to gravity $\left(\mathrm{ft} / \mathrm{sec}^{2}\right)$, and

$x$ is the distance between accelerometers $\mathrm{A}$ and $\mathrm{B}(\mathrm{ft})$.

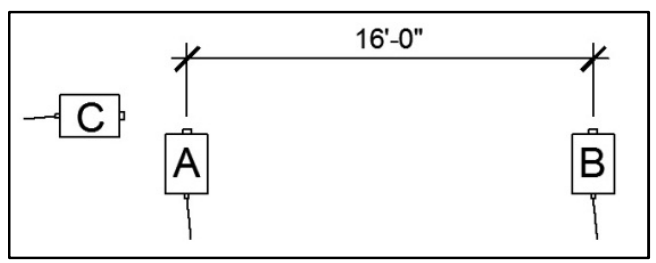

Figure G: Accelerometer Orientation

The distance of $16^{\prime}$ is chosen because this distance produces values for rotation $\left(\mathrm{rad} / \mathrm{sec}^{2}\right)$ similar in magnitude to the translational accelerations (units of $\mathrm{g}$ ) and can therefore be plotted on the same scale as the rest of the readings. A 24-bit analog to digital converter is used to process the signals from the accelerometers. These signals are processed further using the standard lab software, LabView. The software is set up to scale the readings from each accelerometer and provide a time history of the accelerometer readings as well as perform a Fast Fourier Transform (FFT) of the data to provide frequency information.

\subsection{Testing Procedure}

There are three main parts of the experimental procedure; ambient vibration testing, forced vibration testing, and mode shape mapping. In Ambient Vibration Testing (AVT), accelerations are taken of the building subject to everyday forces such as wind and pedestrian traffic. To perform an AVT, a location on the building diaphragm is

Determination of the Modal Parameters of a Five Story Reinforced Concrete Structure Using Ultra-Low Level Excitation and Computational Analysis 
Introduction 10

chosen and the accelerometers are set in the arrangement shown in Figure G. The result of this test is a FFT. A typical AVT FFT is shown in Figure K. An AVT FFT provides the frequencies present in the ambient motion and the directions (NS, EW, and rotation) associated with those frequencies. The accelerometers are set to filter out frequencies above and below significant structural vibrations (above $20 \mathrm{~Hz}$ and below $1 \mathrm{~Hz}$ ). A test runs for 120 seconds; after ten tests the results are averaged to produce a graph like the one shown in Figure K.

In a Forced Vibration Test (FVT) the shaker is set to oscillate at a given amplitude over a range of frequencies. The range of frequencies can be determined from the AVT; for this experiment the range of interest was 2-5 Hz. Like the AVT, the result of an FVT is a FFT at a given location due to a given shaker location and orientation. The difference between and AVT and a FVT is that a FVT can provide a clearer picture of the building's frequencies because choosing a shaker location and orientation, allows control over which frequencies/mode shapes are being excited. Like the AVT, the accelerometers are set to filter out frequencies above and below significant structural vibrations. The shaker is set to oscillate over the desired range of frequencies in 120 seconds; after ten tests the results are averaged to produce a final FFT plot. Since a FVT provides control over which frequencies/mode shapes are being excited (through strategic placement and orientation), it is used to determine the optimal shaker location that will isolate a given frequency/mode. As will be discussed in section 2.0, determining this location is the main challenge of the experimental procedure.

\footnotetext{
Determination of the Modal Parameters of a Five Story Reinforced Concrete Structure Using Ultra-Low Level Excitation and Computational Analysis
} 
Introduction 11

Once the shaker location and orientation that will isolate a given mode are

determined, the third part of the testing procedure, mode shape mapping, is performed.

The shaker is placed at the location/orientation previously determined from the FVT and set to oscillate at the frequency of the target mode. With the shaker running, accelerations are recorded across the entire diaphragm. This is called mode shape mapping and it is the process of setting up the accelerometers as shown in Figure $G$ at several locations across the diaphragm to obtain acceleration magnitudes and directions. This data is then used to describe what will be referred to as an Apparent Mode Shape (AMS). An AMS is the mode shape derived from the raw acceleration data. The word 'apparent' is used here to emphasize the fact that every mode is present in an AMS, with the target mode having the most influence. In order to remove the influence of the other modes, the sweeping procedure described in section 2.0 is utilized. The sweeping procedure produces what will be referred to as Experimental Mode Shapes (EMS), the mode shapes that are used in the comparison with the computational mode shapes. All mode shapes are described at the center of mass with an NS, EW, and rotational component.

While taking readings, the relative directions of the acceleration magnitudes are an important distinction that can only be made by observing the time histories of each reading. The readings from each accelerometer appear as a constant sinusoidal wave with the $y$-axis representing acceleration (in units of $\mu \mathrm{g}$ ) and the $\mathrm{x}$-axis representing time. Half periods of a typical time history from accelerometers $\mathrm{A}, \mathrm{B}$, and $\mathrm{C}$ are shown in Figure $\mathrm{H}$.

\footnotetext{
Determination of the Modal Parameters of a Five Story Reinforced Concrete Structure Using Ultra-Low Level Excitation and Computational Analysis
} 


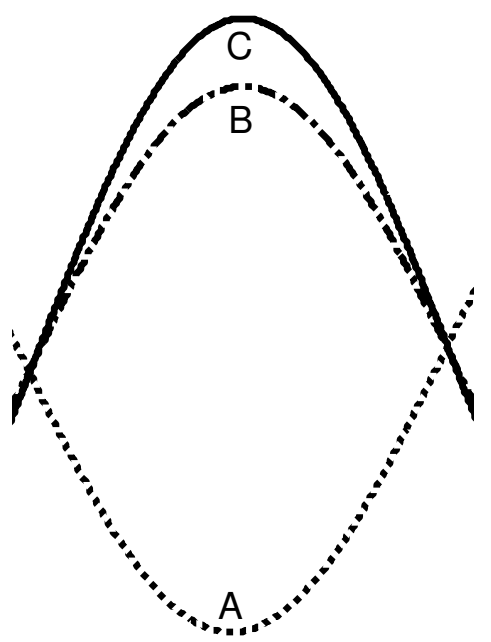

\section{Figure H: Half Period of Accelerometer Time Histories}

As can be seen, the readings may be completely in phase with each other or completely out of phase with each other. Readings that are in phase with each other indicate acceleration in the same direction. For instance, in Figure $\mathrm{H}$, accelerations from accelerometers $\mathrm{B}$ and $\mathrm{C}$ are in phase with each other and out of phase with accelerations from accelerometer A. These readings describe the motion shown in Figure I below.

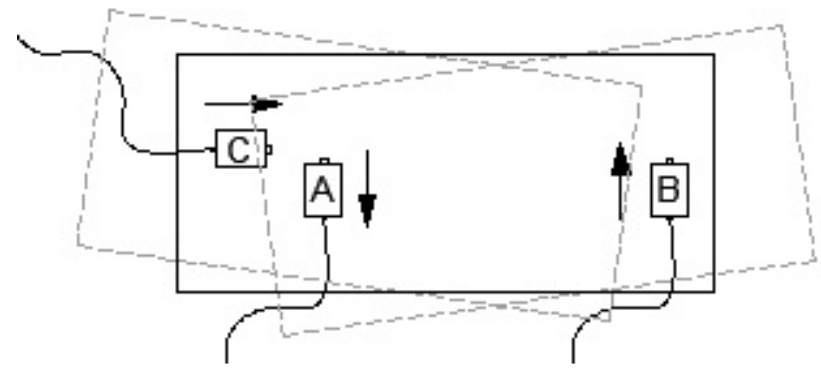

Figure I: Relative Acceleration Directions

Determination of the Modal Parameters of a Five Story Reinforced Concrete Structure Using Ultra-Low Level Excitation and Computational Analysis 
Experimental Basis 13

\subsection{EXPERIMENTAL BASIS}

The experimental goal of this thesis is to determine the first three natural frequencies and mode shapes of the Kennedy Library. The first three modes of most buildings exhibit cantilever-like deformation. Just as a cantilever deflects the most at the top, the displacements of the first three modes of a building are greatest at the highest level. This deflection profile suggests that the linear shaker should be placed at the top level of the library. This placement will excite the cantilever-like deformation of the first three modes.

\subsection{Theoretical Validation of the Experimental Readings}

The most important question related to testing this particular building is the ability of the small shaker (capable of producing 30 pounds of force) to excite such a large building to any measurable extent. There are several theoretical arguments to support that it can. First is the principle of dynamic amplification, the basis of forced vibration testing. Second, by comparing acceleration readings of the building subject to ambient forces to those of the building subject to forced vibration, it can be seen that the building is responding to the shaker. Third, a theoretical forced vibration modal analysis can validate the magnitudes and relative directions of recorded accelerations.

The principle of dynamic amplification is that building response can be amplified due to harmonic excitation at the building's natural frequencies. The differential equation that governs the forced harmonic vibration response for systems with damping is given in Equation 2 (Chopra 2007).

\footnotetext{
Determination of the Modal Parameters of a Five Story Reinforced Concrete Structure Using Ultra-Low Level Excitation and Computational Analysis
} 


$$
m \ddot{u}+c \dot{u}+k u=p_{o} \sin \omega t
$$

Where $p_{o}$ is the amplitude of the force,

$\omega$ is the exciting frequency,

$m$ is the mass of the system,

$k$ is the stiffness of the system,

$c$ is the damping constant,

$u$ is the displacement of the system,

$\dot{u}$ is the velocity of the system, and

$\ddot{u}$ is the acceleration of the system.

The solution to the differential equation is given in Equation 3 (Chopra 2007).

$$
u(t)=e^{-\xi \omega_{n} t}\left(A \cos \omega_{D} t+B \sin \omega_{D} t\right)+C \sin \omega t+D \cos \omega t
$$

Where $\xi$ is the damping ratio,

$\omega_{n}$ is the natural frequency of the system,

$\omega_{D}$ is given by Equation 4, and

$A, B, C, D$ are constants determined by standard procedures (Chopra 2007).

$$
\omega_{D}=\omega_{n} \sqrt{1-\xi^{2}}
$$

The first two terms of Equation 3 make up the transient response and the last two terms represent the steady state response of the system. Since the transient response dies out before it can be measured, only the steady state response is considered. This omission results in Eq. 5.

$$
u(t)=C \sin \omega t+D \cos \omega t
$$

Where $C$ and $D$ are:

$$
C=\frac{p_{o}}{k} \frac{1-\left(\omega / \omega_{n}\right)^{2}}{\left[1-\left(\omega / \omega_{n}\right)^{2}\right]^{2}+\left[2 \xi\left(\omega / \omega_{n}\right)\right]^{2}}
$$

Determination of the Modal Parameters of a Five Story Reinforced Concrete Structure Using Ultra-Low Level Excitation and Computational Analysis 


$$
D=\frac{p_{o}}{k} \frac{-2 \xi \omega / \omega_{n}}{\left[1-\left(\omega / \omega_{n}\right)^{2}\right]^{2}+\left[2 \xi\left(\omega / \omega_{n}\right)\right]^{2}}
$$

This equation can be represented in the simplified form shown in Equation 8.

$$
u(t)=\frac{p_{o}}{k} R_{d} \sin (\omega t-\phi)
$$

Eq. 8

Where $R_{d}$ is the dynamic amplification given by Equation 9, and $\phi$ is the phase shift given by Equation 10 .

$$
\begin{gathered}
R_{d}=\frac{1}{\sqrt{\left[1-\left(\omega / \omega_{n}\right)^{2}\right]^{2}+\left[2 \xi\left(\omega / \omega_{n}\right)\right]^{2}}} \\
\phi=\tan ^{-1} \frac{2 \xi\left(\omega / \omega_{n}\right)}{1-\left(\omega / \omega_{n}\right)^{2}}
\end{gathered}
$$

Solving Equation 9 with $\omega=\omega_{n}$ and $\xi=0.018$ (the experimentally determined first mode damping ratio) gives a dynamical amplification $\left(\mathrm{R}_{\mathrm{d}}\right)$ of 27.5 (the dynamic amplification factor is plotted in Figure $\mathrm{J}$ on the next page for a range of excitation frequencies, $\omega$ ). Given that 30 pounds of force isn't much compared to a building that weighs rougly 20,000 tons, amplifying its effects by 27.5 provides measureable acceleration readings.

\footnotetext{
Determination of the Modal Parameters of a Five Story Reinforced Concrete Structure Using Ultra-Low Level Excitation and Computational Analysis
} 


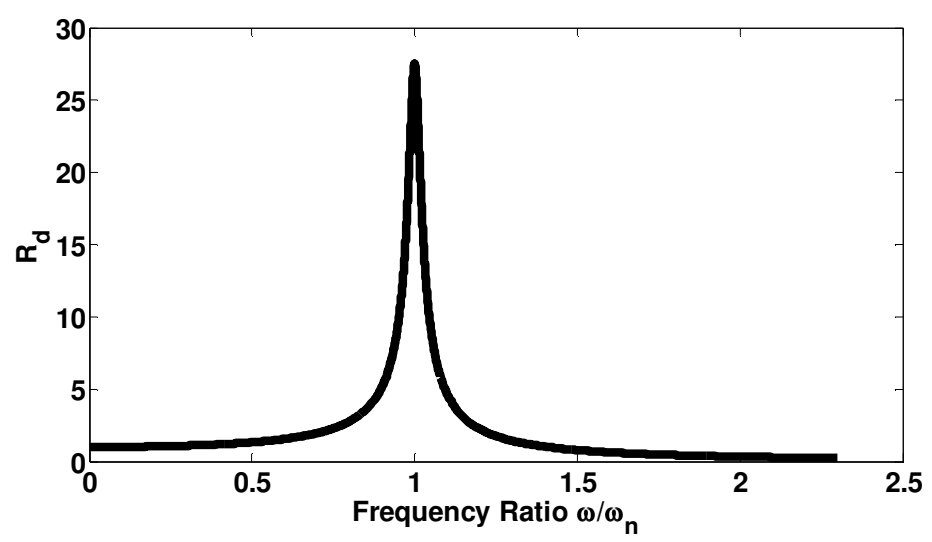

Figure $J: \mathbf{R}_{d}$ for $1.8 \%$ damping

The next question to consider is the magnitudes of the building's ambient accelerations relative to the accelerations induced by the shaker. An AVT was done at a specific location on the fifth floor and the resulting FFT is shown in Figure K. As described in section 1.5, an AVT FFT graphically shows the frequencies present in the ambient motion at a specific location and the directions (NS, EW, and rotation) associated with these frequencies.

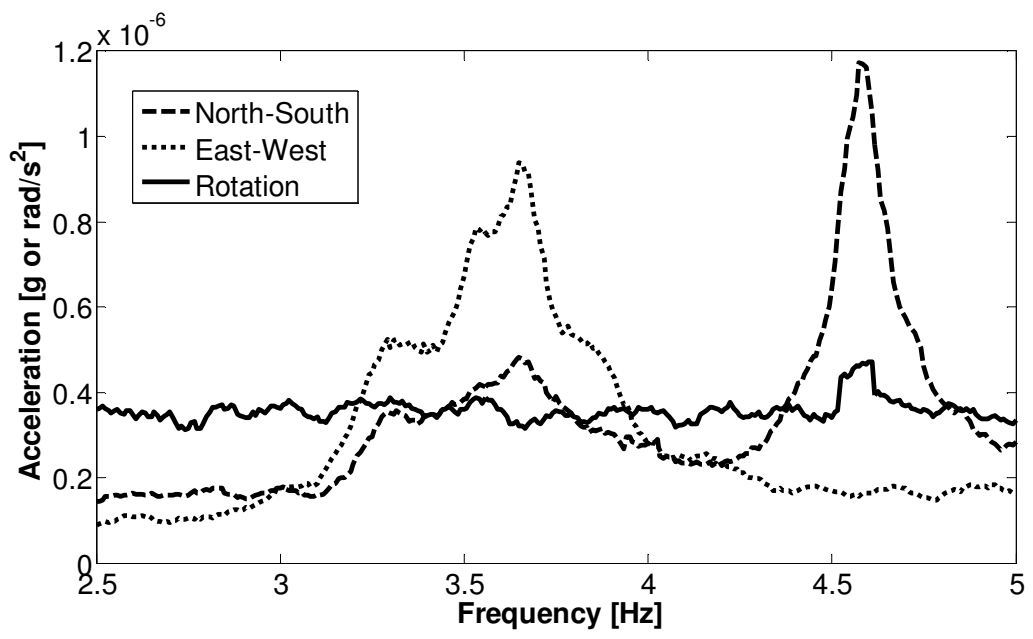

Figure K: AVT at the 5th Floor

Determination of the Modal Parameters of a Five Story Reinforced Concrete Structure Using Ultra-Low Level Excitation and Computational Analysis 
Figure $\mathrm{K}$ shows an apparent peak at $3.65 \mathrm{~Hz}$ and the motion is primarily in the EW direction. Next, the shaker was set at the location where the AVT was performed, oriented in the EW direction and set to oscillate at $3.65 \mathrm{~Hz}$. Shown in Figure $\mathrm{L}$ are the EW readings induced by the shaker overlaid on Figure K. The use of the shaker amplified the accelerations of Figure K by 26.9.

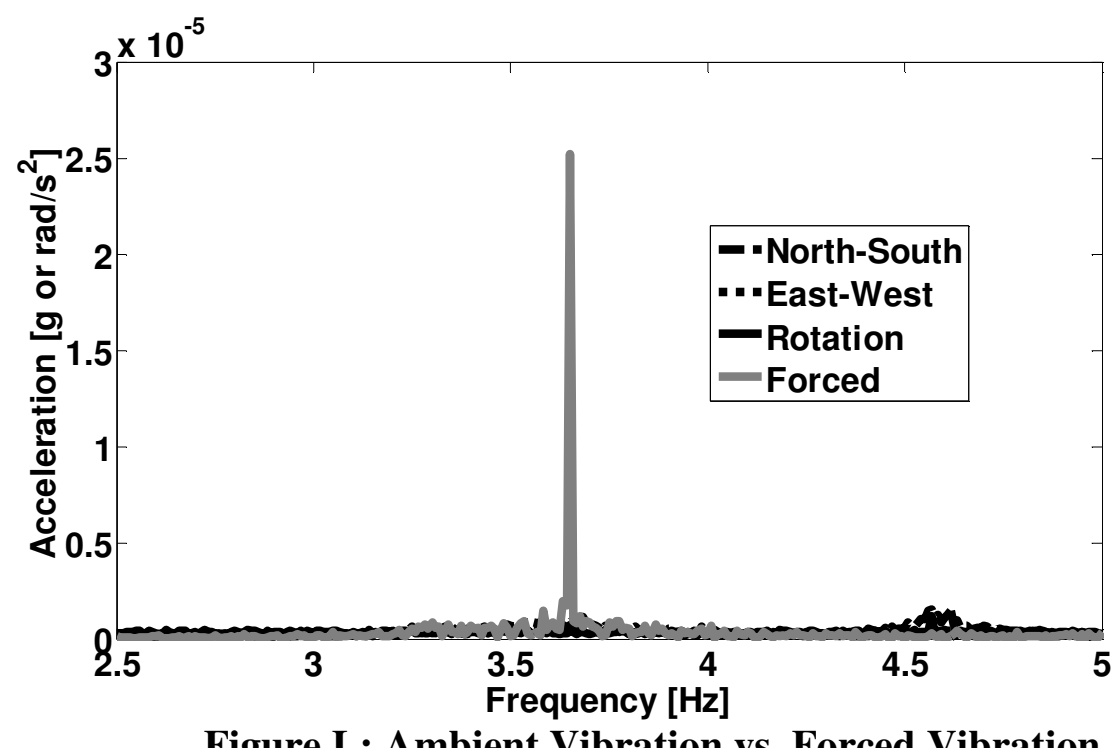

Figure L: Ambient Vibration vs. Forced Vibration

The next verification of the accelerometer readings is an analytical forced vibration modal analysis that simulates the experimental set-up. Shown in Figure M is an illustration of the computational set-up.

Determination of the Modal Parameters of a Five Story Reinforced Concrete Structure Using Ultra-Low Level Excitation and Computational Analysis 


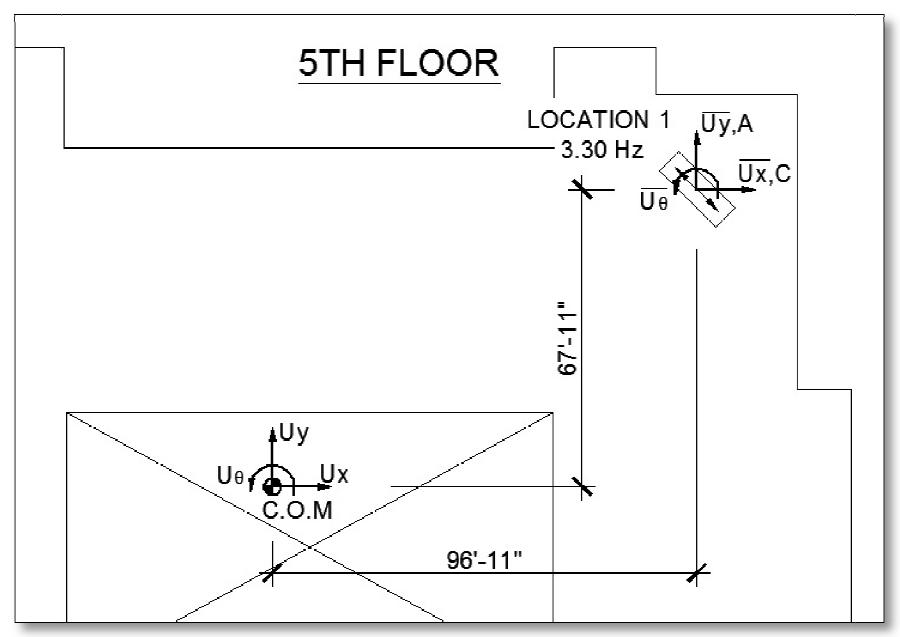

Figure M: Computational Set-up

The 30-pound shaker was set at the north-eastern corner of the building oriented as shown in Figure M. Accelerations at accelerometers A and C, shown in Figure $\mathrm{M}$ were then computed using a modal analysis. The experimentally determined natural frequencies and mode shapes were used in the analysis. Equation 8 in terms of modal coordinates is provided below. This equation was used to determine the modal accelerations (Chopra 2007):

$$
\ddot{q}_{n}(t)=\frac{-p_{n}}{k_{n}} R_{d} \omega^{2} \sin \left(\omega t-\phi_{n}\right)
$$

Where $\ddot{q}_{n}(t)$ is the acceleration in mode $\mathrm{n}$,

$k_{n}$ is equal to $\omega_{n}^{2}$ when mode shapes are mass orthonormalized, and $p_{n}$ is the effect of the loading on mode $\mathrm{n}$, given in Equation 12.

$$
p_{n}=\phi_{n}^{T} p
$$

Where $p$ is the loading vector that describes the shaker location/orientation.

\footnotetext{
Determination of the Modal Parameters of a Five Story Reinforced Concrete Structure Using Ultra-Low Level Excitation and Computational Analysis
} 
With the modal accelerations now defined, the next step is to recouple the equation of motion by using Equation 13 below.

$$
\ddot{u}(t)=\Phi q
$$

Where $\ddot{u}(t)$ is a vector of global acceleration values, and

$\Phi$ is the matrix of mode shapes.

The results of this analysis are provided in Table 1 below. The accelerations determined experimentally at these same locations are also provided.

\section{Table 1: Experimental vs. Computational Accelerations}

\begin{tabular}{|c|c|c|c|}
\hline Accelerometer & $\begin{array}{c}\text { Computational } \\
\text { Accelerations }\end{array}$ & $\begin{array}{c}\text { Experimental } \\
\text { Accelerations }\end{array}$ & $\%$ Difference \\
\hline $\mathrm{A}$ & $27.69 \mu \mathrm{g}$ & $30.90 \mu \mathrm{g}$ & 10.4 \\
\hline $\mathrm{C}$ & $-22.36 \mu \mathrm{g}$ & $-25.52 \mu \mathrm{g}$ & 12.4 \\
\hline
\end{tabular}

The results show a close correlation between the theoretical and experimental values. Analytical values for accelerations are within about $10 \%$ of the measured experimental values, but more importantly, the relative directions of the accelerations match. Such close values suggest the experimental readings are accurate.

\subsection{Ambient Vibration Testing}

The first step in the testing procedure is to perform an AVT. An AVT provides an unbiased (not influenced by the shaker) look at the frequencies present in the ambient motion at a given location. The location chosen for the first AVT was at the east side of the building at the $5^{\text {th }}$ floor. The goal of this location was to obtain the range of frequencies of the first three modes. Note that this information could have been obtained

\footnotetext{
Determination of the Modal Parameters of a Five Story Reinforced Concrete Structure Using Ultra-Low Level Excitation and Computational Analysis
} 
Experimental Basis 20

from numerous AVT locations across the diaphragm. The accelerometers were placed in the set-up shown in Figure $\mathrm{N}$ below.

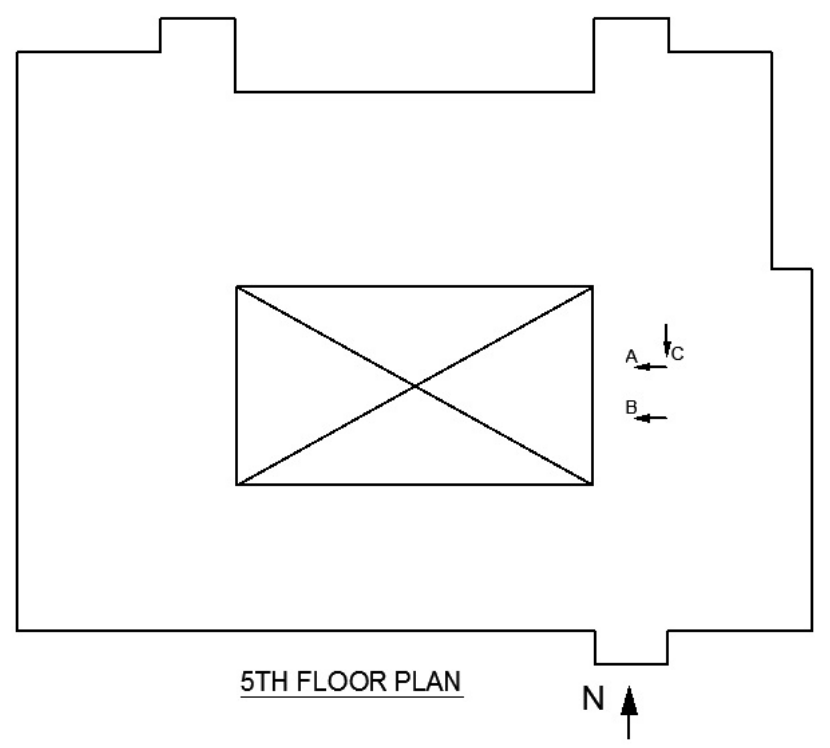

Figure N: Location of Accelerometers for Ambient Reading

Figure O below shows the AVT FFT at this location.

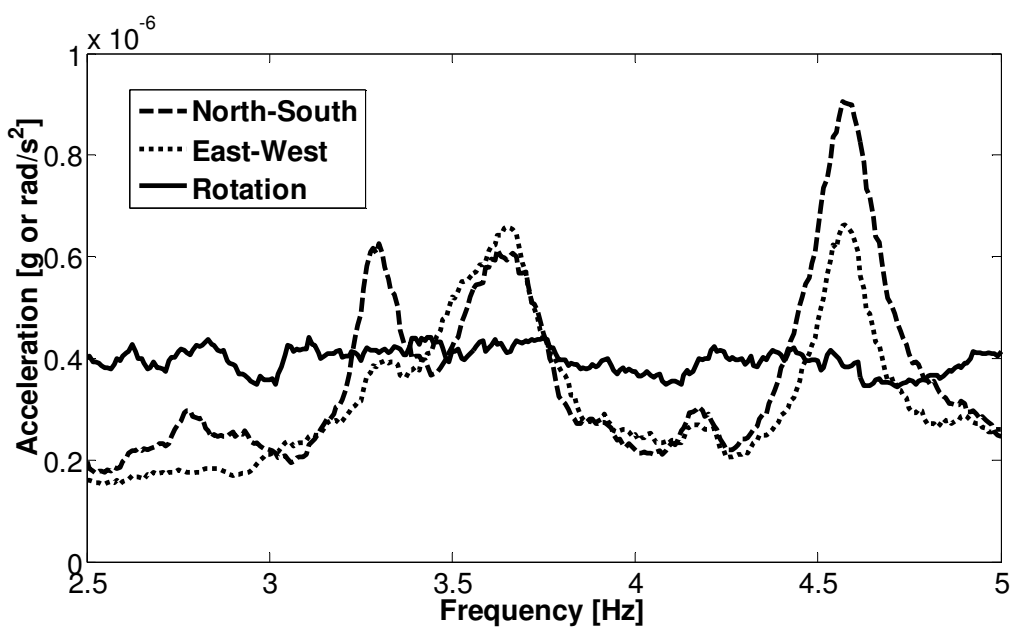

Figure O: Ambient Vibration FFT Response

Determination of the Modal Parameters of a Five Story Reinforced Concrete Structure Using Ultra-Low Level Excitation and Computational Analysis 
Experimental Basis 21

Natural frequencies show up on the FFT as rounded peaks and appear to occur at $3.30,3.65$, and $4.56 \mathrm{~Hz}$. The natural frequency at $3.30 \mathrm{~Hz}$ appears to be primarily NS at this location. The frequencies at 3.65 and $4.56 \mathrm{~Hz}$ appear to have motion in both the NS and EW direction.

\subsection{Experimental Determination of Apparent Mode Shape 1}

With the range of natural frequencies determined from the AVT (AVTs were performed at the southern, northern and western portions of the library to confirm this frequency range), forced vibration sweeps were performed to attempt to isolate the first mode.

The first mode of a regular building is typically translational. Translational modes can be isolated by shaker locations at the center of mass and in line with the center of rigidity. Since the center of mass was located within the atrium, it was not accessible and the shaker had to be placed elsewhere. The center of rigidity was not known during testing, so finding shaker locations that would excite the translational modes had to be determined experimentally, through trial and error.

The location chosen for the first forced vibration sweep was at the north side of the building, slightly east of the center as shown in Figure P. The FVT was run as described in section 1.5 and the resulting FFT is shown in Figure Q. The peaks in Figure Q are at the same locations as those determined from the ambient vibration test (see Figure $\mathrm{O}$ ) and there appears to be no missing or additional information. The orientation of the shaker at a 45-degree angle was chosen to excite as many modes as possible. This

\footnotetext{
Determination of the Modal Parameters of a Five Story Reinforced Concrete Structure Using Ultra-Low Level Excitation and Computational Analysis
} 
Experimental Basis 22

is because a 45-degree angle provides excitation in both the EW and NS directions simultaneously.

If it is desired by the experimenter to isolate mode 1 , the shaker at a given location/orientation should excite the first natural frequency $(3.3 \mathrm{~Hz})$ as much as possible (resulting in the largest peak on the FFT). In order to find the shaker orientation that produced the largest peak on the FFT, FVTs were performed at this location in both the EW and NS directions; however, the orientation shown in Figure P produced the FFT with the largest peak at $3.3 \mathrm{~Hz}$.

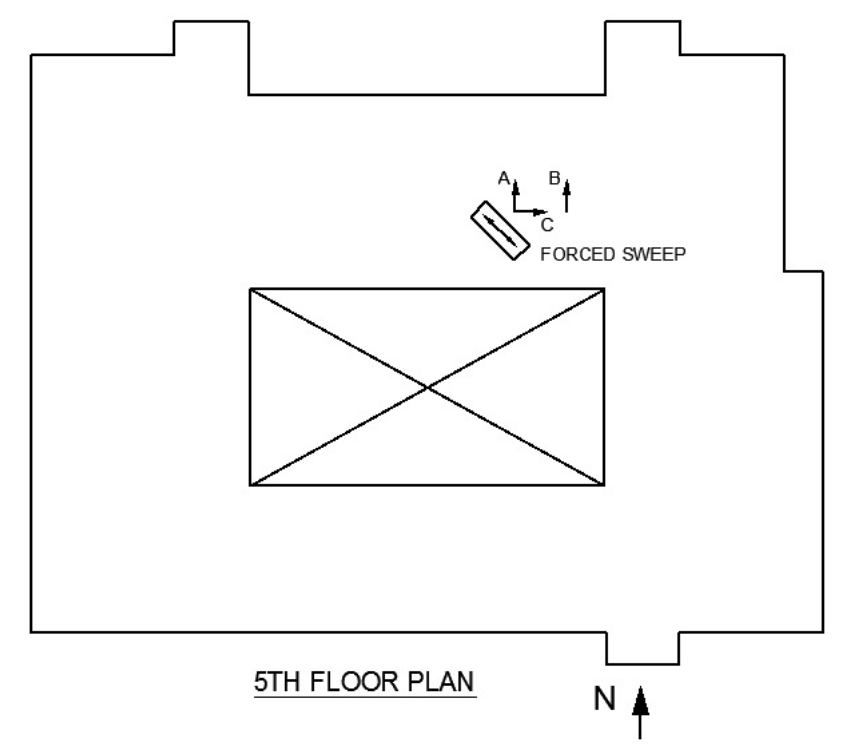

Figure P: Shaker and Accelerometer Location

\footnotetext{
Determination of the Modal Parameters of a Five Story Reinforced Concrete Structure Using Ultra-Low Level Excitation and Computational Analysis
} 


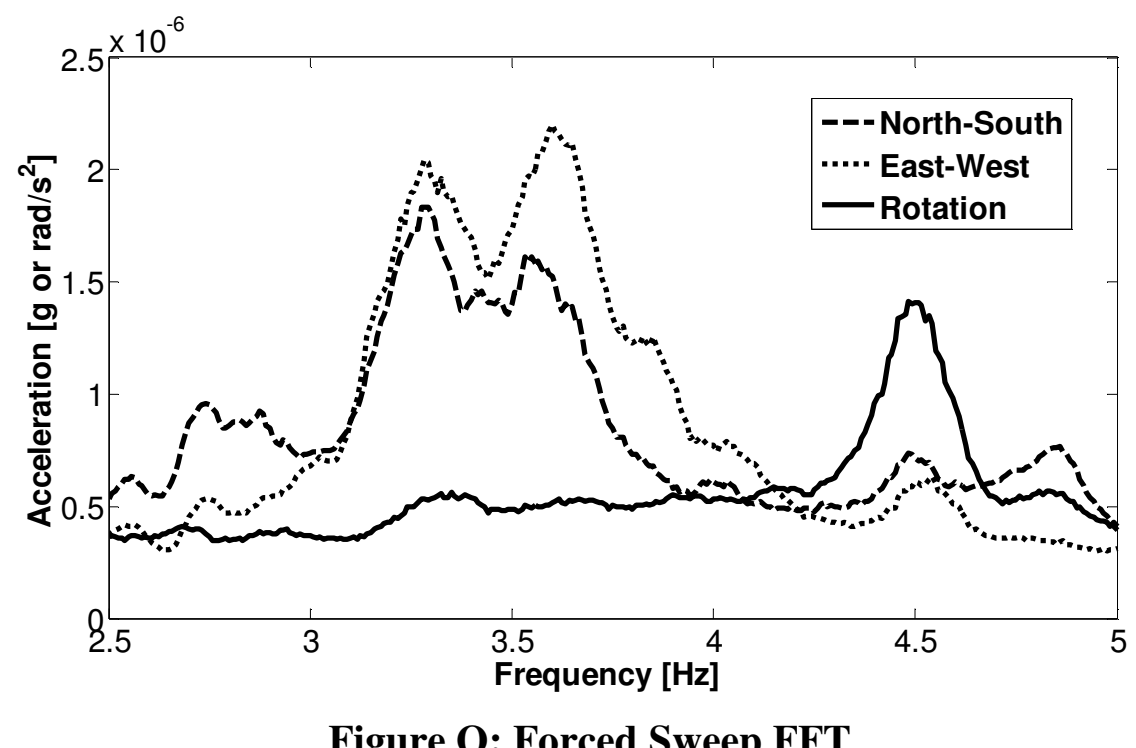

Figure Q: Forced Sweep FFT

Figure Q shows that the first three natural frequencies of this building appear to be at $3.3,3.65$, and $4.56 \mathrm{~Hz}$. The first two natural frequencies are associated with motion in both the EW and NS directions and the third natural frequency is associated with rotation at this location. Also, it is apparent that this shaker location is not ideal for isolating mode 1 . Had this been a good location to isolate mode 1, the FFT would have shown a large peak at $3.3 \mathrm{~Hz}$ and smaller peaks at $3.65 \mathrm{~Hz}$ and $4.56 \mathrm{~Hz}$. Therefore, the next step is to find a better shaker location to isolate mode 1 .

The FFT in figure Q shows that at $3.3 \mathrm{~Hz}$, the building has both EW and NS motion; however, this is not enough information to determine the shaker location and orientation that will isolate mode 1 . In order to do this, more needs to be known about the motion of the diaphragm due to the shaker oscillating at $3.3 \mathrm{~Hz}$ at the current location/orientation. Therefore, acceleration mapping was performed with the shaker oscillating at $3.3 \mathrm{~Hz}$ at the current location/orientation. The resulting acceleration 
magnitudes (represented by the length of the arrows) and directions at several locations are shown in Figure R below.

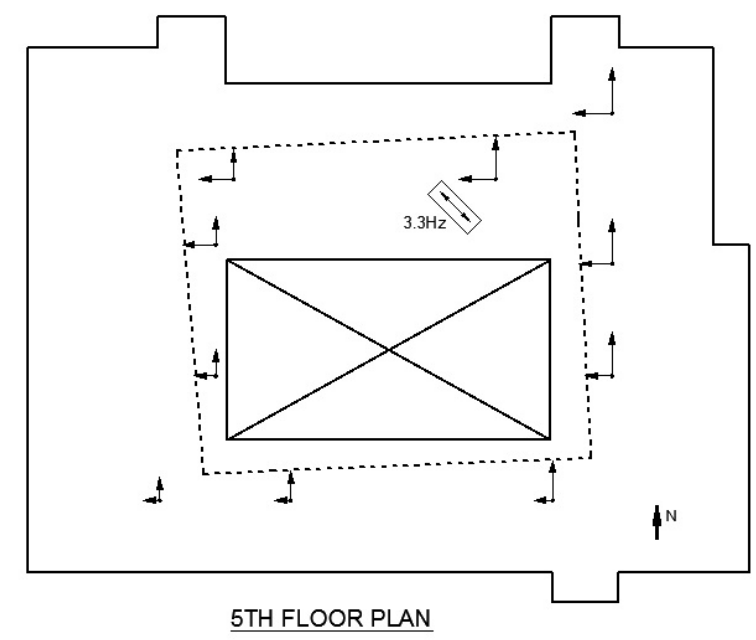

Figure R: Relative Acceleration Values

Figure $\mathrm{R}$ indicates that the largest accelerations are at the north-eastern corner of the diaphragm and that they approach zero at the south-western corner. These accelerations would indicate that a good shaker location to isolate this shape is at the north-eastern corner of the building as shown in Figure S. It is important to note that taking more than one reading is necessary only when the diaphragm is not expected to exhibit rigid behavior. 


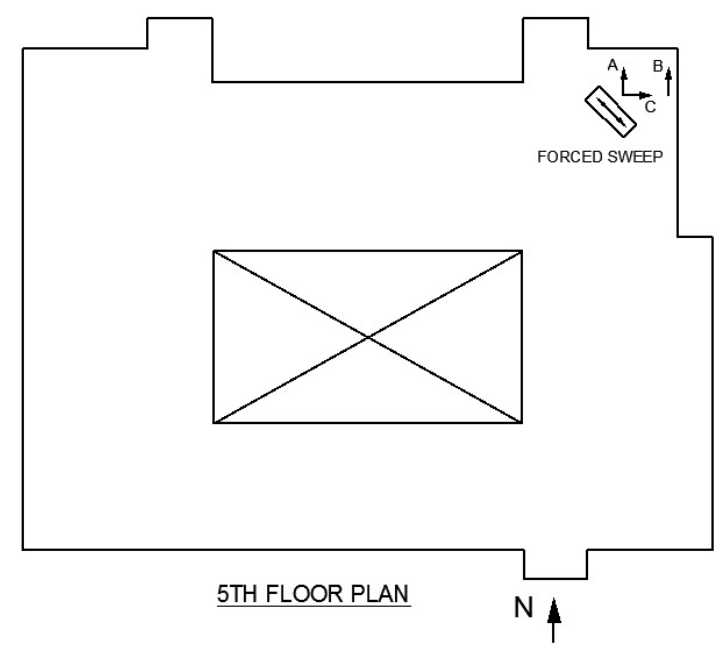

Figure S: Shaker and Accelerometer Location

Figure T below shows the FFT resulting from the forced vibration sweep at the set-up shown in Figure $\mathrm{S}$.

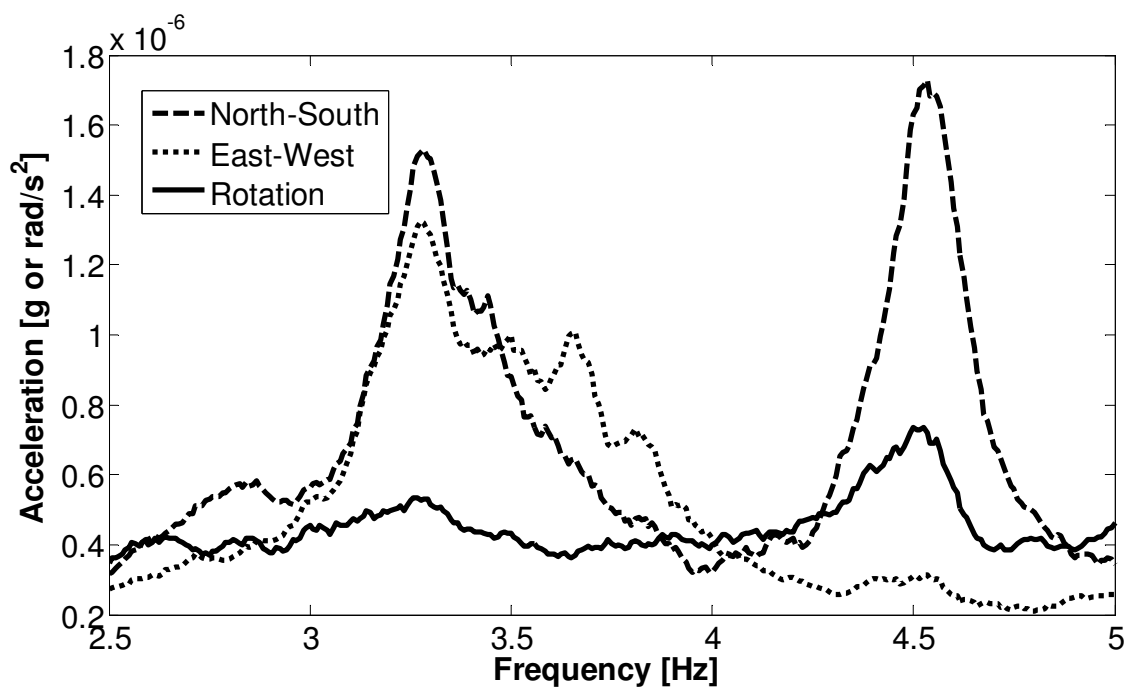

Figure T: Forced Sweep FFT

Figure $\mathrm{T}$ shows that this location is a much better place to isolate the first natural frequency from the second. Had the second natural frequency shown up as a larger peak,

Determination of the Modal Parameters of a Five Story Reinforced Concrete Structure Using Ultra-Low Level Excitation and Computational Analysis 
Experimental Basis 26

forced vibration sweeps would have been performed with different shaker orientations until an orientation was discovered that reduced this peak. Looking again at Figure T, the third natural frequency has a larger influence than at the previous location (see Figure Q). However, complete isolation of a given mode is unlikely if a building is not symmetric. Therefore, this location was chosen to best isolate mode 1. Acceleration mapping of the diaphragm was then performed with the shaker oscillating at $3.3 \mathrm{~Hz}$ at the current location/orientation (shown in Figure $S$ ) to uncover what will be called Apparent Mode Shape 1 (AMS 1). The term apparent is used here to highlight the fact that the acceleration readings are not only due to one mode, but all modes that have directional components common to the directional components excited by the shaker. The results of the acceleration mapping are shown in Figure U. The solid line represents the undeformed position and the dashed line represents apparent mode shape 1.

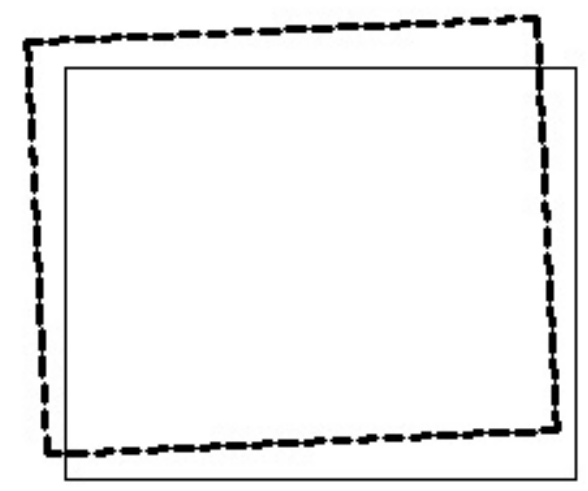

Figure U: Apparent Mode Shape 1

Also, while taking acceleration readings, it was discovered that the diaphragm is essentially rigid in AMS 1. This rigidity was confirmed by constant readings for rotation

Determination of the Modal Parameters of a Five Story Reinforced Concrete Structure Using Ultra-Low Level Excitation and Computational Analysis 
at multiple locations on the diaphragm. Readings for rotation that are different from one location to the next indicate flexibility in the diaphragm.

\subsection{Experimental Determination of Apparent Mode Shape 2}

Locating an appropriate shaker location to isolate mode 2 is simplified by the principle of modal orthogonality. A physical interpretation of modal orthogonality is that the work done by one mode's inertia forces in going through another mode's displacements is zero (Chopra 2007). In other words, all modes have a unique shape that is not present in any other mode. Due to this property, the best location/orientation for shaker location 2 would mimic the complete opposite motion of apparent mode shape 1. Therefore, the shaker location chosen to isolate the second mode was at the NW side of the building oriented at a 45-degree angle as shown in Figure V.

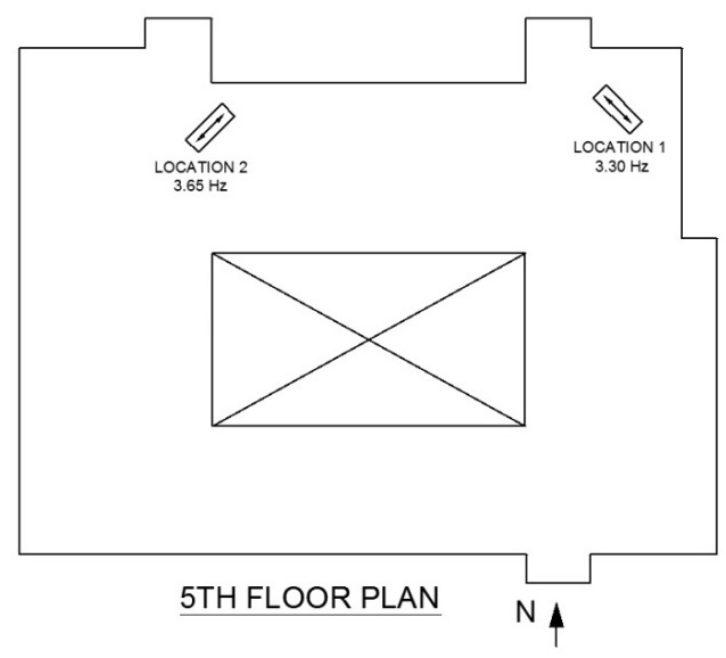

Figure V: Shaker Locations 1 and 2

Determination of the Modal Parameters of a Five Story Reinforced Concrete Structure Using Ultra-Low Level Excitation and Computational Analysis 
The FFT at shaker location 2 is shown in Figure W.

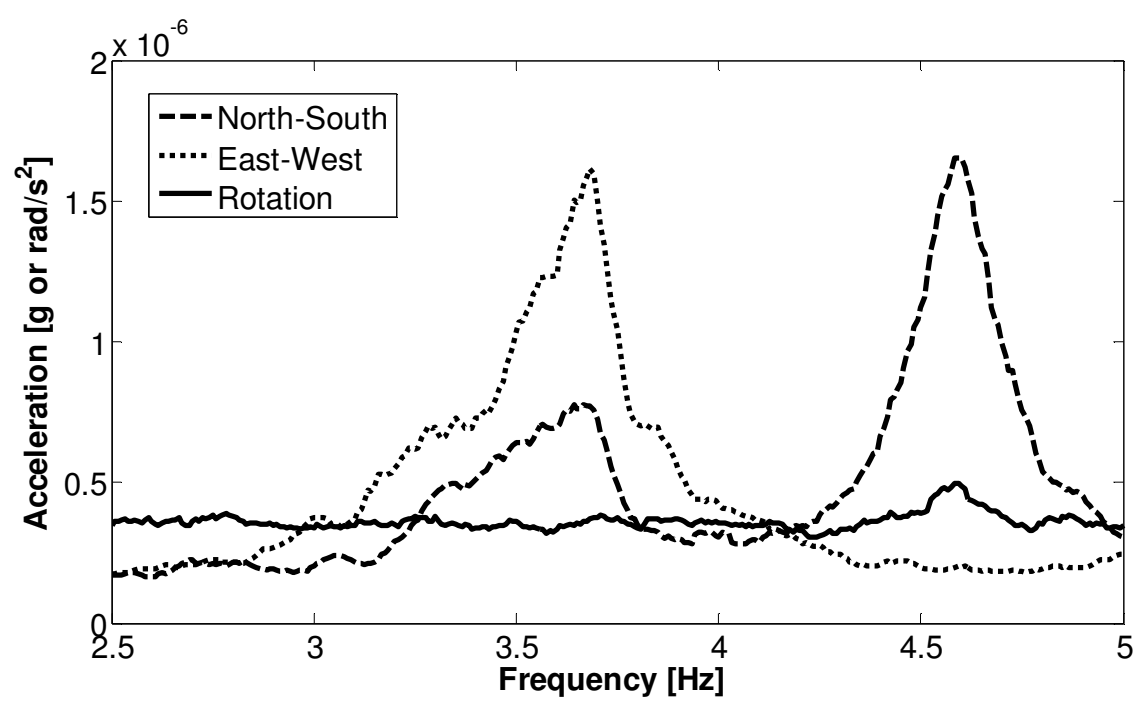

Figure W: FFT at Shaker Location 2

Leaving the shaker at location 2 and setting it to oscillate at $3.65 \mathrm{~Hz}$, apparent mode shape 2 was mapped. Apparent mode shape 2 is shown in Figure X. It is primarily a diagonal motion from the SW corner to the NE corner of the building with very little rotation. Like apparent mode shape 1, apparent mode shape 2 is a rigid diaphragm motion.

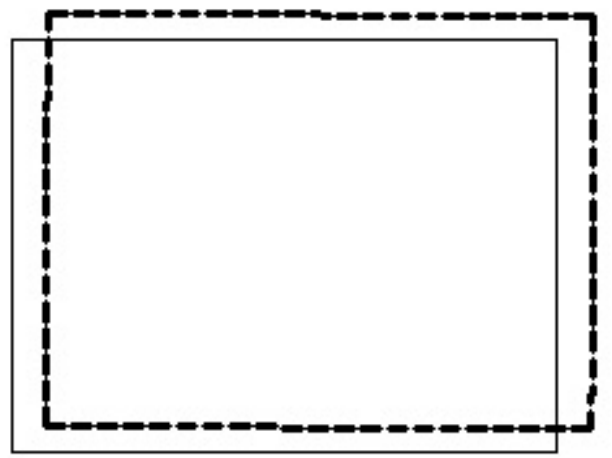

Figure X: Apparent Mode Shape 2

Determination of the Modal Parameters of a Five Story Reinforced Concrete Structure Using Ultra-Low Level Excitation and Computational Analysis 


\subsection{Experimental Determination of Apparent Mode Shape 3}

Apparent mode shape 3 was the most peculiar of the three modes because it exhibited flexible diaphragm behavior. The shaker location that would excite a shape orthogonal to apparent mode shapes 1 and 2 is not easy to visualize; therefore, shaker location 3 was chosen based on the FFTs resulting from forced vibration sweeps performed at several locations. Shaker location 3, shown in Figure Y produced the FFT with the best isolation of the third natural frequency from the first two.

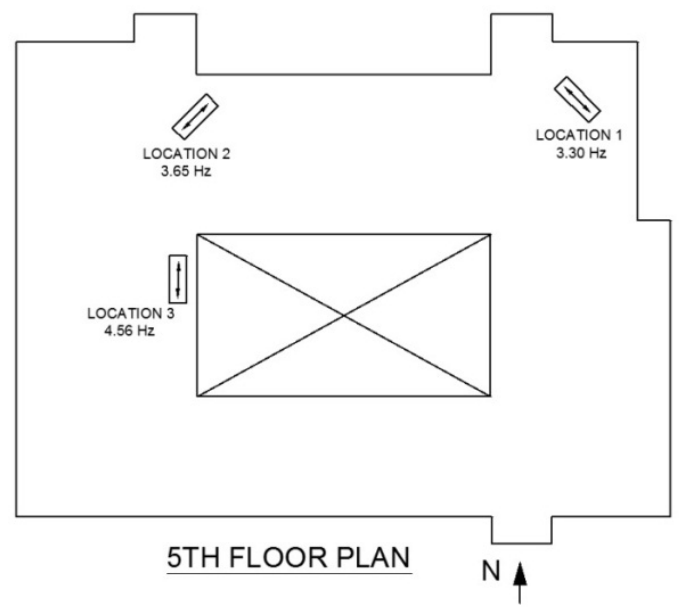

Figure Y: Shaker Locations 1, 2 and 3

The FFT at shaker location 3 is shown in figure $\mathrm{Z}$ on the next page.

Determination of the Modal Parameters of a Five Story Reinforced Concrete Structure Using Ultra-Low Level Excitation and Computational Analysis 


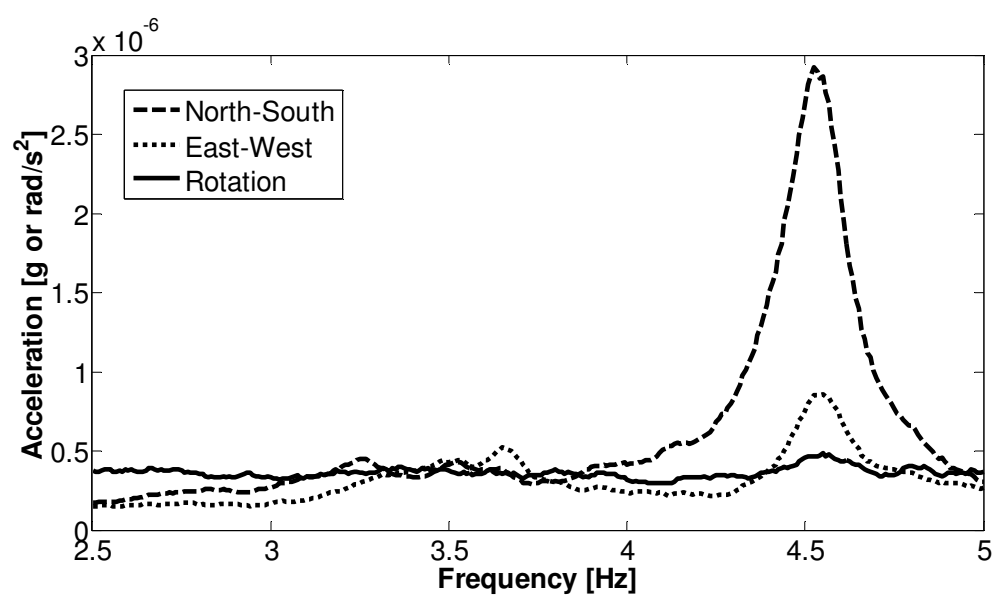

Figure Z: FFT at Shaker Location 3

The results of Figure $\mathrm{Z}$ are peculiar because both the first and second apparent mode shapes have NS components of motion; therefore, larger peaks should be expected at their respective natural frequencies. The reason the peaks at 3.3 and $3.56 \mathrm{~Hz}$ appear small is because shaker location 3 isolates the third natural frequency better than shaker locations 1 and 2 isolate the first and second natural frequencies. For instance, by comparing Figures Z, T and W, it is obvious that the magnitudes of acceleration that shaker locations 1 and 2 induce at 3.3 and $3.56 \mathrm{~Hz}$ are about half of what shaker location 3 induces at $4.56 \mathrm{~Hz}$. These relative magnitudes of acceleration mean that even though the peaks at 3.3 and $3.56 \mathrm{~Hz}$ in figure $\mathrm{Z}$ are at about $0.5 \mu \mathrm{g}$, they are only slightly less than half of their largest potential peaks (about 1.6 $\mu \mathrm{g}$ in figures $\mathrm{T}$ and $\mathrm{W}$ ).

The results of the acceleration mapping due to the shaker oscillating at $4.56 \mathrm{~Hz}$ at shaker location 3 are shown in Figure AA on the next page. The solid line represents the 
Experimental Basis 31

undeformed position and the dashed line represents the deformed position (based on recorded accelerations). There is significant flexibility in this apparent mode shape; the east side and the west side of the library move opposite to each other in the NS direction. This flexibility is also the reason why finding shaker location 3 was done in a trial-anderror fashion. The flexibility made it so that the shaker location and orientation weren't representative of the shape that it excited (representative in the sense that the shape could be easily deduced by the shaker's positioning).

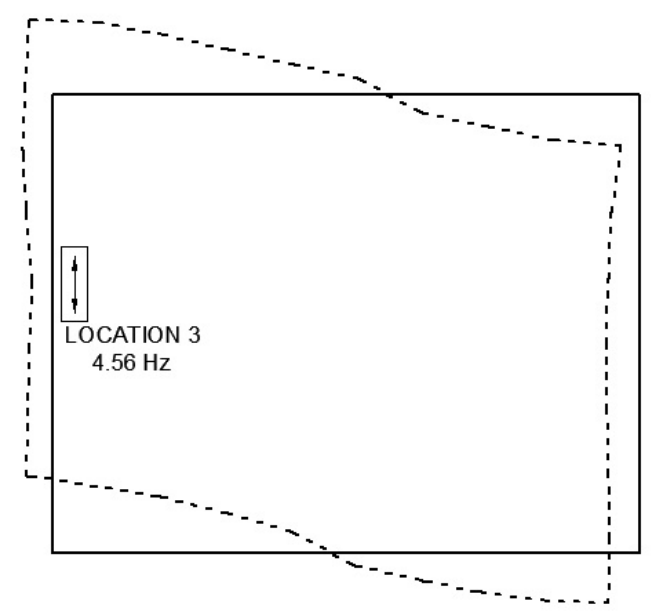

Figure AA: Flexibility in Apparent Mode Shape 3

Unlike the first and second apparent mode shapes, accelerometer readings were taken at $16^{\prime}$ increments around the entire diaphragm to capture the flexible behavior of AMS 3. Also, in order to describe this shape with only three coordinates at the center of mass, it was necessary to approximate the shape as a rigid body. Figure BB on the next page shows this approximation. The solid line represents the same qualitative acceleration readings as the dashed line in Figure AA, and the bold dashed line represents 
Experimental Basis 32

the rigid body approximation. Figure CC shows apparent mode shape 3 . This rigid body approximation is necessary for ease of comparison with the analytical results which will be presented in section 3.0.

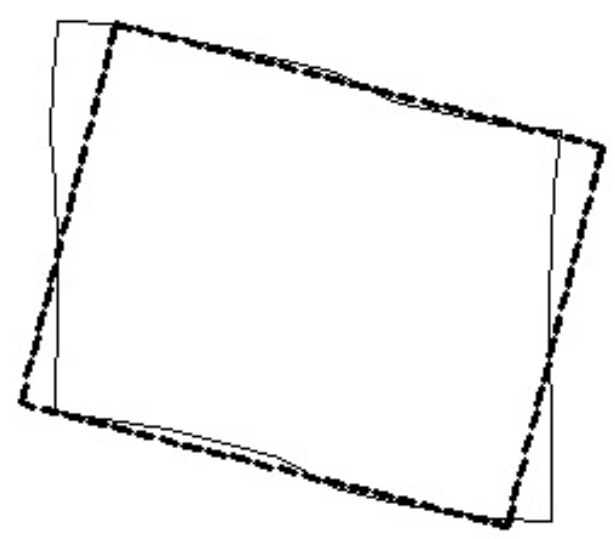

Figure BB: Flexibility in Apparent Mode Shape 3

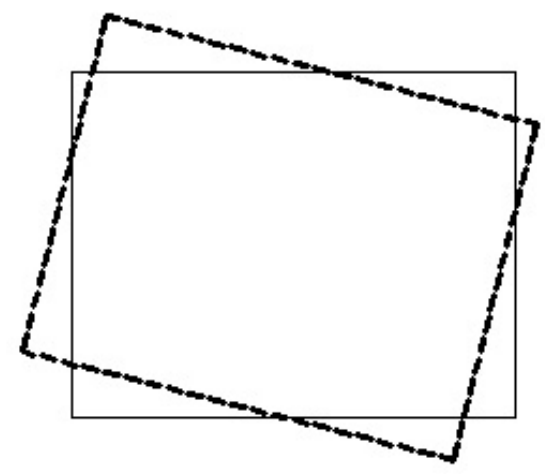

Figure CC: Apparent Mode Shape 3

\subsection{Floor-to-Floor Variation of Apparent Mode Shapes 1, 2 and 3}

Readings at the other floor levels were taken to determine the floor-to-floor variation of the apparent mode shapes. A plot of the acceleration values at the different levels of the Library is provided in Figure DD on the next page. These readings were taken at the NE corner of the library with the shaker oscillating at $3.3 \mathrm{~Hz}$ at location 1

Determination of the Modal Parameters of a Five Story Reinforced Concrete Structure Using Ultra-Low Level Excitation and Computational Analysis 
Experimental Basis 33

(see Figure Y). The solid lines represent data that was recorded and the dashed lines represent interpolated data.

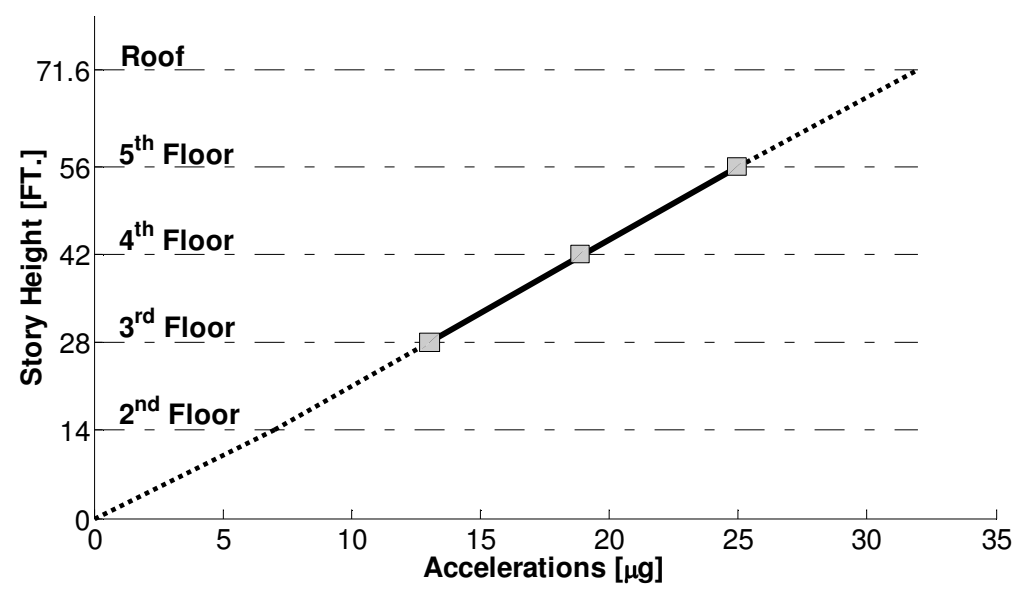

Figure DD: Vertical Variation of Accelerations for AMS 1 at N-E Corner of Library

Figure DD shows that the relative floor-to-floor displacements of apparent mode shape 1 are cantilever-like; the largest displacement is at the top level, reducing to zero at the base. As expected, this was also the general trend in apparent mode shapes 2 and 3.

In order to ensure that the shaker was exciting the same shape at the other floor levels, the response of the entire diaphragm at levels 4 and 3 due to the shaker oscillating at the $5^{\text {th }}$ floor at all three shaker locations was also recorded. By following the same mapping procedure previously described, the shapes were confirmed to be the same as those recorded on the $5^{\text {th }}$ floor. The difference was that the readings decreased by roughly $20 \%$ from the $5^{\text {th }}$ to the $4^{\text {th }}$ floor and again from the $4^{\text {th }}$ to the $3^{\text {rd }}$ floor. To confirm that the different levels were moving in phase with one another, accelerometers were placed at the same location and oriented in the same direction simultaneously on the two different floors. If the readings from the accelerometers were in phase with each other, it

Determination of the Modal Parameters of a Five Story Reinforced Concrete Structure Using Ultra-Low Level Excitation and Computational Analysis 
Experimental Basis 34

could be concluded that the two levels were moving together. Readings were not taken at the $2^{\text {nd }}$ floor because the accelerations at this level were not enough above ambient vibration to be considered useful. Readings were not taken at the roof level because access was not available.

\subsection{Modal Orthogonality of the Apparent Mode Shapes}

As mentioned in section 2.4, an important property of natural modes is the principle of modal orthogonality. This principle requires an additional step in the experimental determination of the mode shapes. As previously noted, the shapes that were derived experimentally were apparent mode shapes. Apparent mode shapes aren't the pure mode shapes (they weren't exactly orthogonal to each other), they are simply the shapes corresponding to a specific shaker location, orientation, and frequency. Even though the shaker was oscillating at the building's natural frequencies, the location and orientation of the shaker excited other modes; and the reason that the other modes were excited was because they are coupled in shape. For instance, because all three modes have an $\mathrm{x}, \mathrm{y}$ and rotational displacement, it is impossible to find a shaker location/orientation that will completely isolate one mode from the others.

The test for orthogonality of two modes is called the modal assurance criterion (MAC). In this experiment a mass-weighted modal assurance criterion is used (McDaniel and Archer 2010a). The MAC compares two modal vectors and results in a number between 0 and 1 . Two orthogonal modes have a MAC number of 0 and two identical modes have a MAC number of 1 . The mass-weighted MAC formula is provided in Equation 14.

Determination of the Modal Parameters of a Five Story Reinforced Concrete Structure Using Ultra-Low Level Excitation and Computational Analysis 


$$
M A C=\frac{\left(\phi_{i}^{T} M \phi_{j}\right)^{2}}{\left(\phi_{i}^{T} M \phi_{i}\right)\left(\phi_{j}^{T} M \phi_{j}\right)}
$$

Where $\phi_{i}$ and $\phi_{j}$ represent the two mode shapes being compared, and $M$ is the mass matrix of the structure.

Table 2 below gives the mass weighted MAC numbers that compare the three apparent mode shapes (AMS) to one another.

Table 2: Mass Weighted MAC Numbers Comparing the Apparent Mode Shapes

\begin{tabular}{|c|c|c|c|}
\hline AMS & 1 and 2 & 1 and 3 & 2 and 3 \\
\hline $\begin{array}{c}\text { Mass Weighted MAC } \\
\text { number }\end{array}$ & 0.0076 & 0.9832 & 0.0463 \\
\hline
\end{tabular}

Table 2 shows an inconsistency between what these numbers suggest and what is known about the apparent mode shapes. It implies that while AMS 2 is not excited by the shaker oscillating at shaker location 3 at $4.65 \mathrm{~Hz}$, AMS 1 is. However, AMS 2 also has displacement in the NS direction (the same orientation as the shaker at location 3). The modal analysis outlined in section 2.0 is revisited next to examine the results of Table 2 .

Table 3 on the next page shows the relevant modal information for the modal analysis. The analytical mode shapes (see section 3.0) described at the center of mass for the fifth floor are shown in the second column of Table 3. A 30-pound harmonic load was set to oscillate at $4.56 \mathrm{~Hz}$ at shaker location 3.

\footnotetext{
Determination of the Modal Parameters of a Five Story Reinforced Concrete Structure Using Ultra-Low Level Excitation and Computational Analysis
} 
Experimental Basis 36

\begin{tabular}{|c|c|c|c|c|c|c|c|}
\hline Mode \# & $\begin{array}{l}\text { Mode Shape } \\
\text { Coordinates at } 5 \\
\text { Flr. [ft.;ft.;rad. }\end{array}$ & $\mathrm{R}_{\mathrm{d}}$ & $P_{n}$ & $\mathrm{k}_{\mathrm{n}}$ & $\omega^{2}$ & $\phi_{n}$ & $\frac{-p_{n}}{k_{n}} R_{d} \omega^{2}$ \\
\hline 1 & $\begin{array}{c}-0.0039 \\
0.0096 \\
0.0000 \\
\vdots\end{array}$ & 1.098 & 0.206 & 430 & 821 & -0.055 & -0.43 \\
\hline 2 & $\left.\begin{array}{c}\cdot \\
-0.0100 \\
-0.0058 \\
0.0000 \\
\vdots\end{array}\right\}$ & 1.778 & -0.235 & 526 & 821 & -0.080 & 0.65 \\
\hline 3 & $\left.\begin{array}{c}0.0038 \\
-0.0058 \\
0.0002 \\
\vdots\end{array}\right]$ & 27.5 & -0.447 & 821 & 821 & 1.571 & 12.30 \\
\hline
\end{tabular}

The equation for determining the modal accelerations is repeated below for convenience.

$$
\ddot{q}_{n}(t)=\frac{-p_{n}}{k_{n}} R_{d} \omega^{2} \sin \left(\omega t-\phi_{n}\right)
$$

It is apparent that Equation 11 is dominated by the $p_{n}$ and the $R_{d}$ terms. The equation for $p_{n}$ is repeated here

$$
p_{n}=\phi_{n}^{T} p
$$

Eq. 12

\footnotetext{
Determination of the Modal Parameters of a Five Story Reinforced Concrete Structure Using Ultra-Low Level Excitation and Computational Analysis
} 
Where $p$ is the force vector defined at the center of mass due to the shaker oscillating at the $5^{\text {th }}$ floor at shaker location 3 (see Figure Y). Vector $p$ is provided in Equation 15 below.

$$
p=\left[\begin{array}{c}
0 \\
0 \\
0 \\
0 \\
30 \\
-1627.5 \\
\vdots \\
0
\end{array}\right] l b s .
$$

The last column in Table 3 shows the term that has the most influence on the modal accelerations (it represents the amplitude of the modal accelerations). These numbers suggest that both mode shapes 1 and 2 have very little presence in these readings (the readings that would produce apparent mode shape 3 ). This minor presence contradicts the results of Table 2 on page 34 which imply that mode 1 had a significant presence in apparent mode shape 3.

Plugging the values in Table 3 into Equation 11 provides the modal accelerations. Multiplying these modal accelerations by their respective mode shapes (provided in column 2 of Table 3 ) gives the contribution of each mode to the global accelerations. Adding these accelerations together gives the actual acceleration (the motion that is recorded experimentally by the accelerometers). These global accelerations along with

\footnotetext{
Determination of the Modal Parameters of a Five Story Reinforced Concrete Structure Using Ultra-Low Level Excitation and Computational Analysis
} 
the actual accelerations are provided in Figure EE below for the NS direction. This figure shows that mode 1 should not have had such a presence in AMS 3.

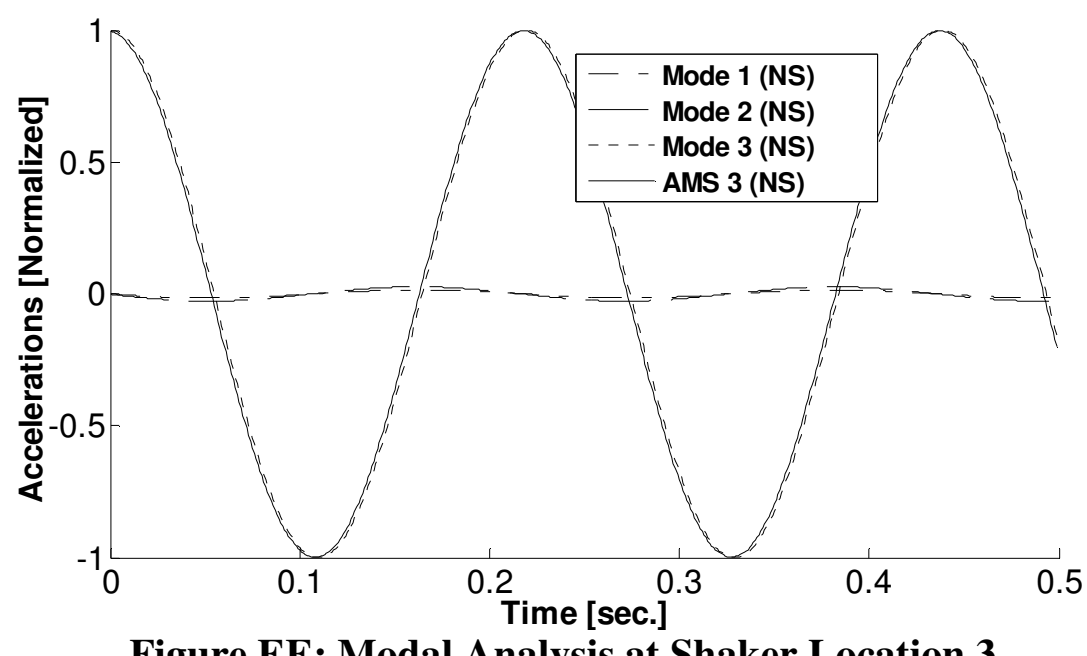

Figure EE: Modal Analysis at Shaker Location 3

There are several things that could have led to the unexpected mass weighted MAC numbers of Table 2. For instance, the presence of higher modes may have influenced the readings, and the idealization of AMS 3 as rigid body motion may have caused some error in the sweeping process. Also, if localized diaphragm flexibility at shaker location 3 exists it would slightly isolate that location from the rest of the building. Lastly, the original shaker locations may not have been the best locations to isolate the mode shapes; meaning new locations could be explored that may decouple the modes further.

Figure FF on the next page shows the shaker locations that should be investigated next. Shaker location 2 (used to isolate mode 2) should be left in its original position because this was a good location to isolate mode 2 from mode 1 (see Figure W). In order

Determination of the Modal Parameters of a Five Story Reinforced Concrete Structure Using Ultra-Low Level Excitation and Computational Analysis 
Experimental Basis 39

to decouple modes 1 and 3 further, shaker location 3 should be moved to where the accelerations for mode 1 are smallest (see Figure R). This location may have the effect of removing the previously noted $1^{\text {st }}$ mode contribution from AMS 3. Shaker location 1 should be moved to the SE corner of the building because this location might excite an AMS 1 that is more orthogonal to AMS 2. Looking again at Figure R, diaphragm motion at the SE corner in mode 1 is primarily NS. Therefore, a NS orientation of the shaker at shaker location 1 in Figure FF should also be investigated because it may produce a purer mode 1 . Shaking at these locations, taking readings every $16^{\prime}$ (to capture flexibility), describing the apparent mode shapes with several (more than three) degrees of freedom per floor, and exploring higher modes, may uncover new behavior that could explain the discrepancy noted earlier in this section.

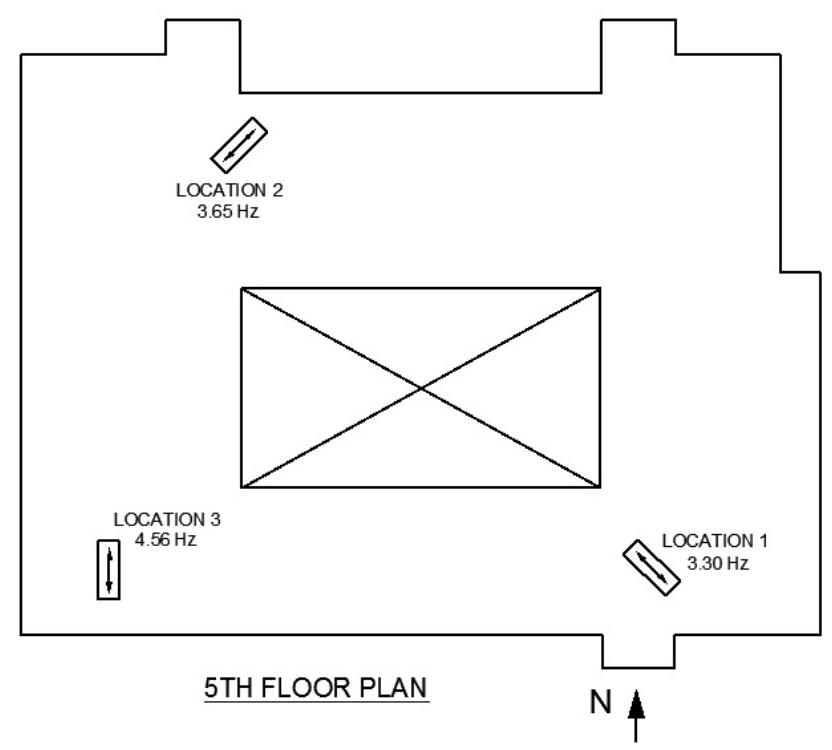

Figure FF: Shaker Locations for Further Investigation

Determination of the Modal Parameters of a Five Story Reinforced Concrete Structure Using Ultra-Low Level Excitation and Computational Analysis 
Experimental Basis 40

\subsection{The Sweeping Procedure}

Looking again at the results in Table 2, there is a large amount of Apparent Mode Shape 1 (AMS 1) in Apparent Mode Shape 3 (AMS 3). Also, AMS 2 is the most orthogonal compared to the other two shapes. This orthogonality means that AMS 2 should be assumed pure and swept from Apparent Mode Shapes 1 and 3. However, this assumption will lead to some discrepancy when final experimental mode shapes are compared with the analytical mode shapes because Apparent Mode Shape 2 isn't truly pure.

Given two mode shapes $\phi_{i}$ and $\phi_{j}$, the formula for sweeping $\phi_{i}$ out of $\phi_{j}$ is the Modified Gram-Schmidt (Golub and Van Loan 1989) provided in equation 16 below.

$$
\phi_{j}^{\prime}=\phi_{j}-\left(\frac{\phi_{i}^{T} M \phi_{j}}{\phi_{i}^{T} M \phi_{i}}\right) \phi_{i}
$$

Where $\phi_{j}^{\prime}$ is the mode shape resulting from sweeping $\phi_{i}$ out of $\phi_{j}$, and $M$ is the mass matrix of the structure.

Since Apparent Mode Shape 2 is assumed pure, it is now referred to as Experimental Mode Shape 2 (EMS 2). Experimental Mode Shape 2 was first swept out of Apparent Mode Shape 1. This sweep resulted in what is now referred to as Experimental Mode Shape 1. Experimental Mode Shape 1 and Experimental Mode Shape 2 were then swept out of Apparent Mode Shape 3 to produce Experimental Mode Shape 3. Table 4 on the next page shows a summary of the Experimental Mode Shapes (EMS). The solid lines represent the undeformed position and the dashed lines represent the deformed position.

Determination of the Modal Parameters of a Five Story Reinforced Concrete Structure Using Ultra-Low Level Excitation and Computational Analysis 


\section{Table 4: Summary of Experimental Mode Shapes}

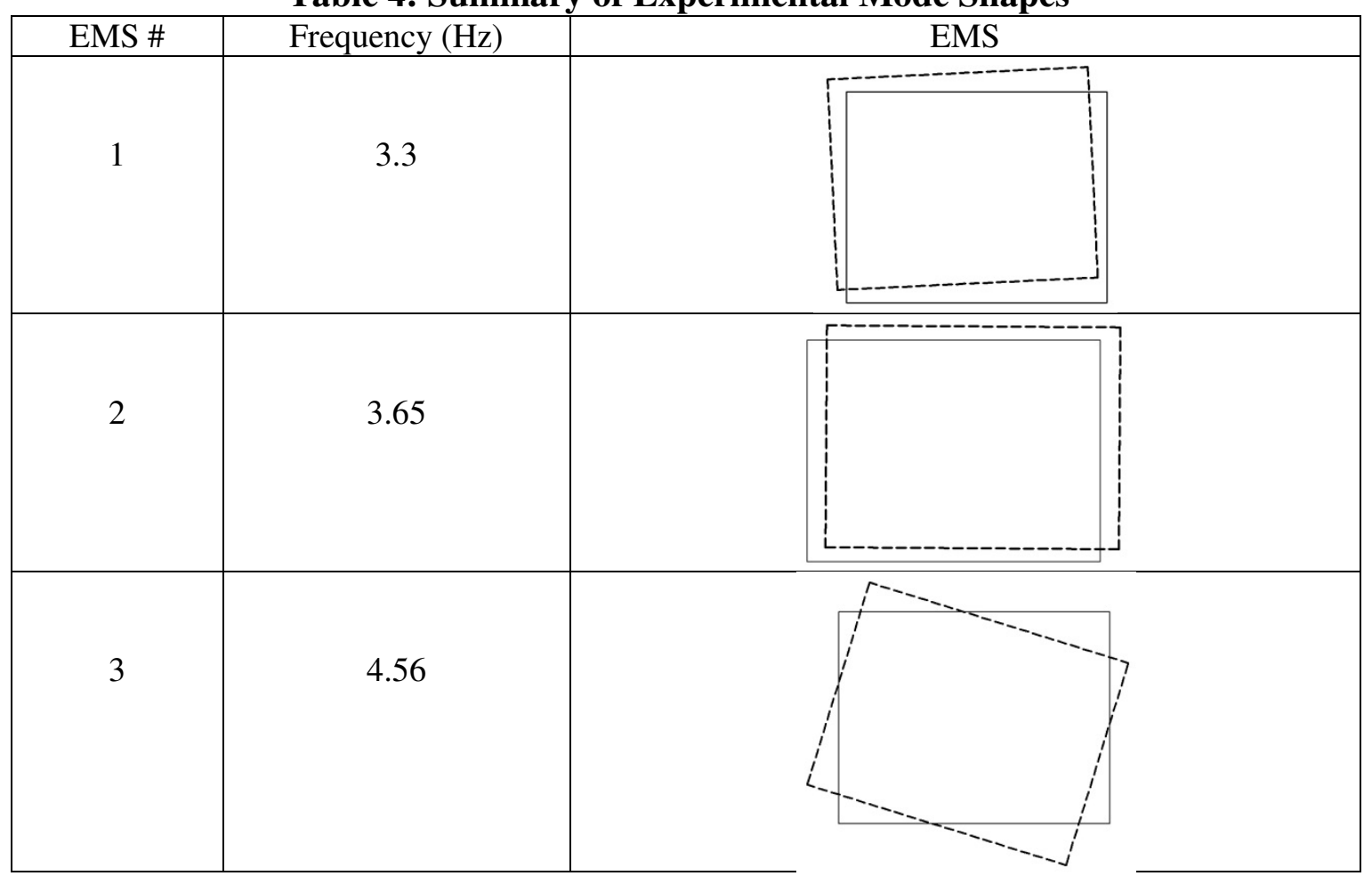

There appears to be little difference between the experimental mode shapes and the apparent mode shapes. For shape 1 this is nearly true, for shape 2 it is completely true, but for shape 3 there is a noticeable difference. The comparison between Apparent Mode Shape 1 and Experimental Mode Shape 1 is shown in Figure GG on the next page. The comparison between Apparent Mode Shape 3 and Experimental Mode Shape 3 is show in Figure $\mathrm{HH}$ on the next page. The dashed lines represent apparent mode shapes and the dotted lines represent the experimental mode shapes.

Determination of the Modal Parameters of a Five Story Reinforced Concrete Structure Using Ultra-Low Level Excitation and Computational Analysis 


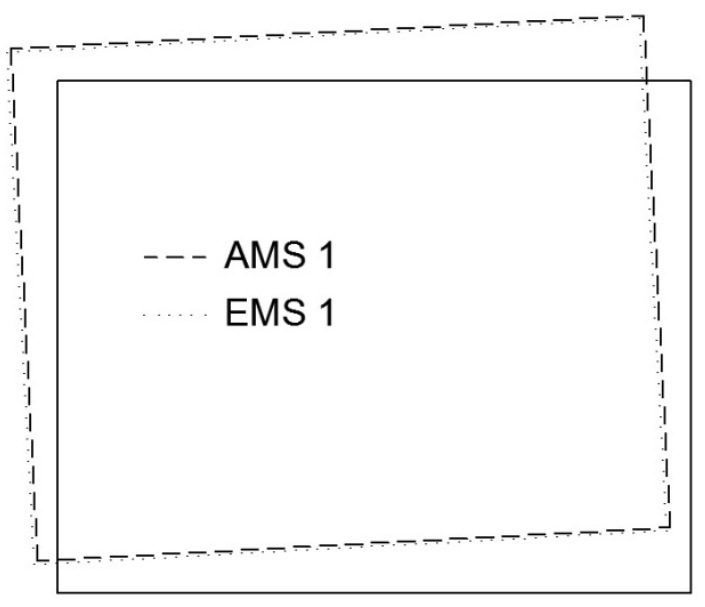

Figure GG: Apparent Mode Shape 1 vs. Experimental Mode Shape 1

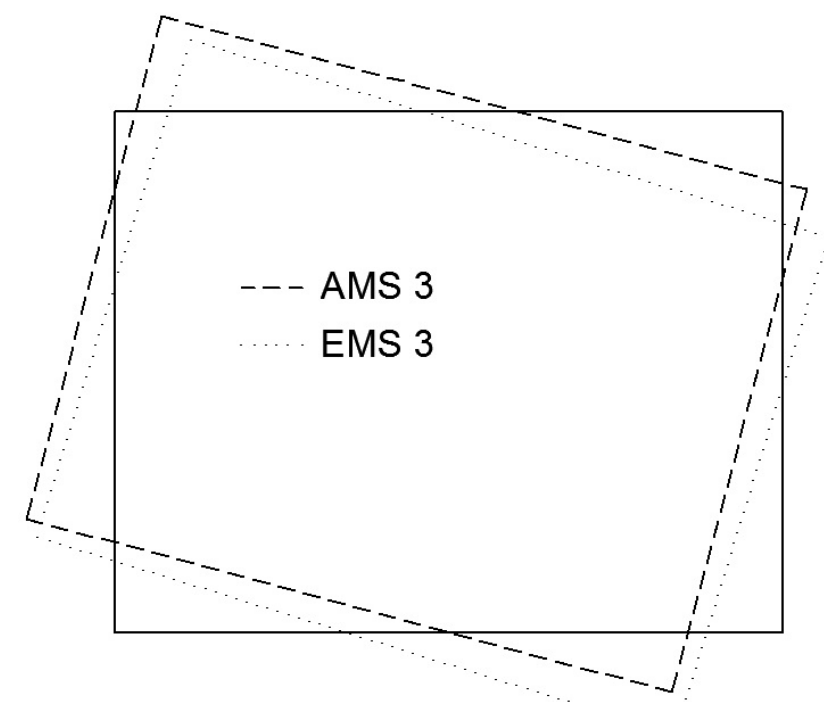

Figure HH: Apparent Mode Shape 3 vs. Experimental Mode Shape 3

\subsection{Experimental Conclusions}

The most significant conclusion from the experimental portion of this paper is the fact that Ultra-Low Forced Vibration Testing (UL-FVT) can generate detectable accelerations throughout a building as massive as the Kennedy Library. Accelerations

Determination of the Modal Parameters of a Five Story Reinforced Concrete Structure Using Ultra-Low Level Excitation and Computational Analysis 
Experimental Basis 43

induced by the shaker were recorded as high as $60 \mu \mathrm{g}$, about 12 times the average ambient acceleration readings. Induced accelerations were detected across the entire diaphragm at the $5^{\text {th }}, 4^{\text {th }}$, and $3^{\text {rd }}$ floors, with the shaker operating at the $5^{\text {th }}$ floor. Readings decreased in acceleration by approximately $20 \%$ per floor. To further validate the readings, a modal analysis was performed to produce theoretical data to compare to the measured accelerations at the same location (and due to the same shaker frequency, orientation and location). Measured acceleration magnitudes matched the theoretical acceleration magnitudes to within about $10 \%$ and the relative directions were the same.

Ambient Vibration Tests (AVT) were used to find the range of the first three natural frequencies. Forced Vibration Tests (FVT) were then performed to find shaker locations/orientations that would isolate each mode. The proper shaker locations for each mode were determined by both trial-and-error and visualizing the motion orthogonal to already gathered data. The validity of the shaker locations was confirmed by performing a Fast Fourier Transform (FFT) of the recorded accelerations and observing the frequencies present in these readings. Mode shape mapping was then used to determine the shape of deformation induced by the shaker oscillating at each location at its respective frequency.

For the Kennedy Library, mapping of the mode shapes was a time consuming effort due to the opening in the diaphragm and the diaphragm flexibility exhibited in the third mode. The opening in the diaphragm also added difficulty in isolating the modes because shaking could not be done at the center of mass. Mode shape mapping resulted in

Determination of the Modal Parameters of a Five Story Reinforced Concrete Structure Using Ultra-Low Level Excitation and Computational Analysis 
Experimental Basis 44

what was referred to as Apparent Mode Shapes (AMS). Apparent Mode Shapes are derived from the measured (global) accelerations. Every mode contributes to an Apparent Mode Shape, with the target mode having the most influence. To obtain the final Experimental Mode Shapes (EMS), the Modified Gram-Schmidt (MGS) was used to sweep out the influence of the other modes from the target AMS.

Once the Apparent Mode Shapes were determined, mass-weighted MAC numbers were calculated to determine the orthogonality of the shapes to each other (see Table 2). Since the building was not symmetric, multiple mode shapes were excited at each natural frequency. These other mode shapes needed to be swept out to determine the actual mode shapes. MAC numbers were used to determine that AMS 2 was the most "pure" of the three Apparent Mode Shapes, and was therefore referred to as EMS 2. EMS 2 was swept out of AMS 1 to produce EMS 1. EMS 1 and EMS 2 were then swept out of AMS 3 to produce EMS 3. The MAC numbers also revealed that there was a large amount of AMS 1 in AMS 3. This result was unexpected and could not be verified by a modal analysis. Since this behavior could not be verified, building behavior may have been missed due poor shaker locations or not adequately described due to using only 3 degrees of freedom per floor to describe the shapes. Future work that may result in more accurate AMS's and EMS's include: exploring new shaker locations (shown in figure FF), describing the mode shapes with more degrees of freedom, and exploring the influence of higher modes.

\footnotetext{
Determination of the Modal Parameters of a Five Story Reinforced Concrete Structure Using Ultra-Low Level Excitation and Computational Analysis
} 
Experimental Basis 45

\subsection{ANALYTICAL BASIS}

The second part of this project was to develop an analytical model that accurately captured the dynamic behavior of the structure. Using the experimentally determined natural frequencies of the previous section as a basis, modeling of the Kennedy Library progressed from a simple hand analysis to an involved computational model.

The first obstacle was coming up with the mass matrix. While the structural plans provided the majority of the information necessary to calculate the total building weight, estimating the live load required more work. To come up with the weight of the books, a sample area of bookshelves was weighed to come up with a uniform weight of $80 \mathrm{psf}$ to use wherever books were located. The weight used for table and desk locations was taken as $25 \%$ of the design live load of $100 \mathrm{psf}$. This percentage was used based on ASCE 7-05 $\$ 12.7 .2$ which states that for areas used for storage, a minimum of $25 \%$ of the floor live load must be included in the effective seismic weight. As mentioned previously, the mass matrix was derived using three degrees of freedom at the center of mass of each floor.

\subsection{Progression of Analytical Modeling}

The analytical modeling of the Kennedy Library was progressive; starting with the simplest assumptions and refining them in order to account for more complex behavior.

The first model assumed a lumped mass at the center of a rigid diaphragm with three degrees of freedom per floor. This model is best illustrated by Figure II . The shear walls were modeled as line elements forced into double bending by an infinitely rigid slab. To keep the model simple so that calculations could be done by hand, shear

Determination of the Modal Parameters of a Five Story Reinforced Concrete Structure Using Low Level Excitation and Computational Analysis 
Experimental Basis 46

stiffness, torsional stiffness, and out-of-plane wall stiffness was omitted. The result was a first mode frequency of $20.1 \mathrm{~Hz}$; significantly far from the experimentally determined frequency of $3.3 \mathrm{~Hz}$. However, the extra stiffness was quickly attributed to the shear walls having height-to-width ratios that were far from slender, meaning that shear provided as much as $90 \%$ of the wall flexibility in some cases.

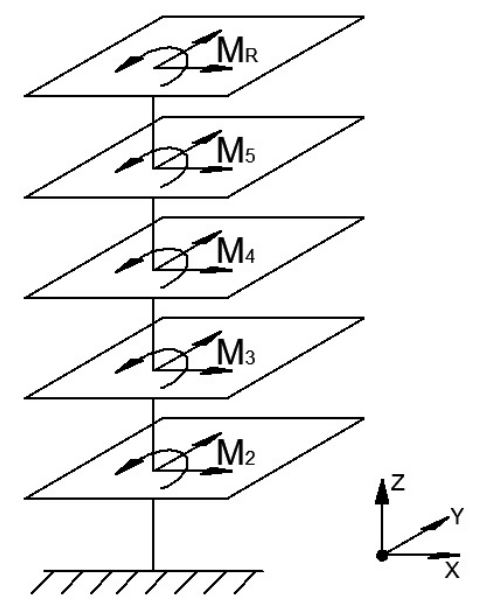

\section{Figure II: Lumped Mass Model}

The next step was then to include shear stiffness and leave everything else constant. This analysis was also able to be done by hand since shear stiffness does not complicate the analysis significantly. The result of the analysis was a first mode frequency of $5.45 \mathrm{~Hz}$ (down from $20.1 \mathrm{~Hz}$ ) making it apparent that shear accounts for most of the flexibility in this structure.

An analysis program was used to adjust the model further. The software used for the analysis was ETABS, a common structural analysis platform. After successfully calibrating the computer model with the previous hand analysis, the model was modified

Determination of the Modal Parameters of a Five Story Reinforced Concrete Structure Using Low Level Excitation and Computational Analysis 
to include torsional stiffness and out-of-plane wall stiffness. The results of the analysis did not change significantly; the first mode frequency was $5.46 \mathrm{~Hz}$, up from $5.45 \mathrm{~Hz}$. This artificially high frequency was due to double bending enforced by rotational constraints at all the floor levels.

The next step was to remove the rotational constraints at the floor levels and allow the walls to interact freely with the slab. As mentioned previously, the floor slabs are a waffle slab/pan joist system. Rather than modeling every joist of the slab, an equivalent thickness was used for the slab so that typical shell elements that model both membrane (in-plane) and plate (out-of-plane) behavior could be used. The result of removing the double bending assumption was a fundamental frequency of $2.56 \mathrm{~Hz}$.

The next concern had to do with the interaction of the wall/line elements with the slab/shell elements. This is illustrated in Figure JJ below.

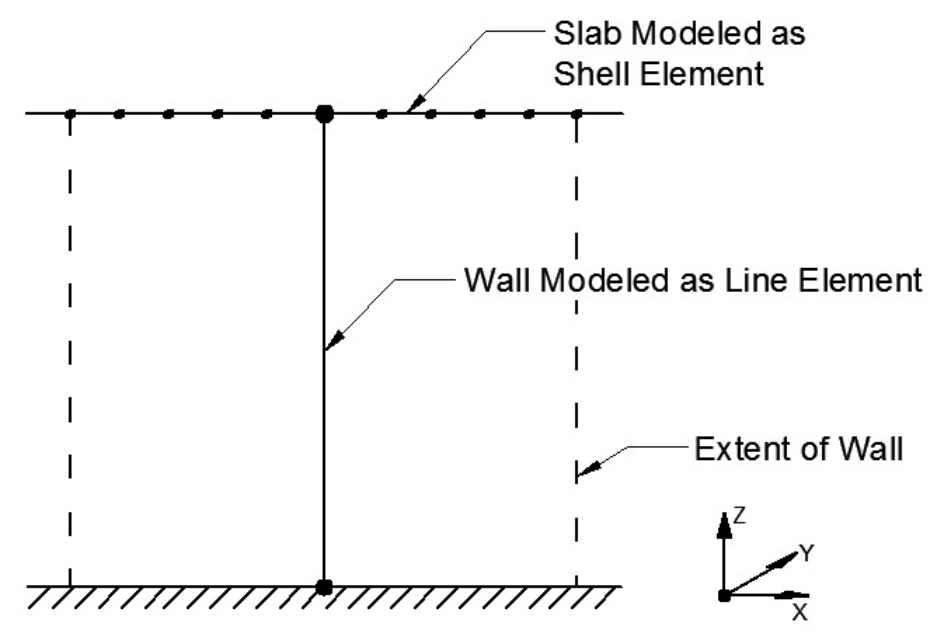

Figure JJ: Modeling Walls as Line Elements

Determination of the Modal Parameters of a Five Story Reinforced Concrete Structure Using Low Level Excitation and Computational Analysis 
Experimental Basis 48

The interaction of this wall-slab configuration shown in Figure JJ is not limited to the point where the centerline of the wall meets the slab. Rather, the interaction occurs along the length of the wall. Without adding additional constraints to this model, the deformed shape is incompatible as shown in Figure KK below.

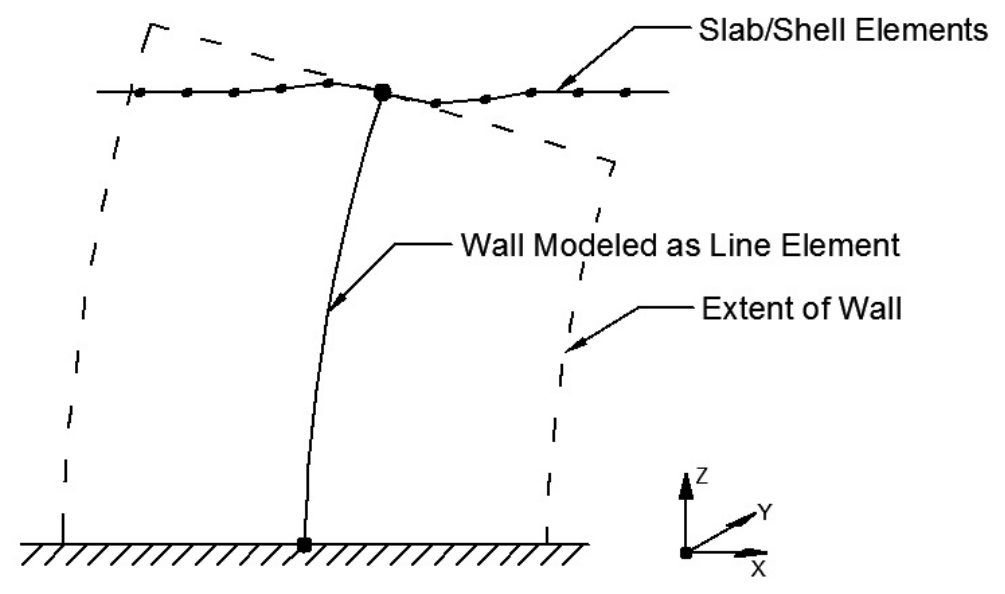

Figure KK: Compatibility Error at Wall/Slab Intersection

By adding an additional element, deformation compatibility was enforced. This additional element was a line element, rigid in flexure in the plane of the wall (i.e. Ry is infinite). It was assigned to connect the centerline of the wall/line element to the slab/shell elements along the length of the wall. Adding this element provided the wallslab deformation compatibility shown in Figure LL on the next page.

Determination of the Modal Parameters of a Five Story Reinforced Concrete Structure Using Low Level Excitation and Computational Analysis 


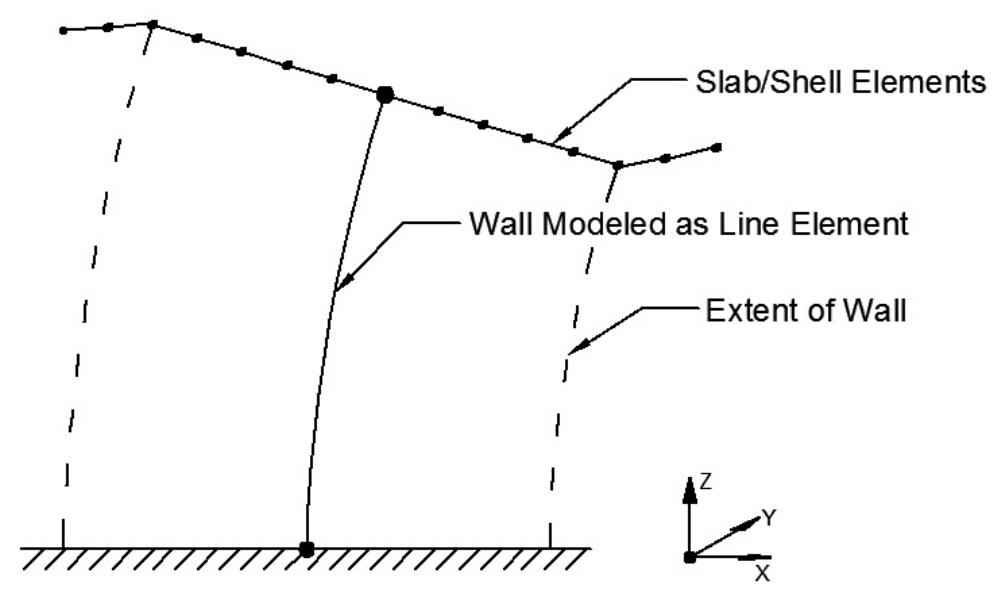

Figure LL: Rigid Constraints at Wall/Slab Intersection

Adding these constraints to the model raised the fundamental frequency to $2.87 \mathrm{~Hz}$ (up from $2.56 \mathrm{~Hz})$.

The next issue to consider was properly modeling the $\mathrm{C}, \mathrm{T}$, and L shaped walls. The current model treated all wall assemblages as separate, disconnected line elements. Constructing the wall assemblages in this manner led to high underestimation of the flexural and torsional stiffness of the walls. To address this issue, a model that explicitly modeled the geometry of the walls was implemented. This model made use of the same shell elements used for the slab to model the walls. The resulting fundamental frequency from this analysis model was $3.65 \mathrm{~Hz}$ (up from $2.87 \mathrm{~Hz}$ ). As expected, the stiffness of the model significantly increased by explicitly modeling the wall cross sections.

Upon further investigation on the use of these shell elements to model shear wall behavior, it was discovered that the shell elements were inadequate for modeling torsion (Wilson 2002). To confirm the inadequacy, the $12^{\prime}-0 "$ tall by $22^{\prime}-6 "$ long wall shown in 
Figure MM on the next page was analyzed with a 10,000 kip-in torque applied at its centroid. The wall was analyzed both as a line element and as finely meshed shell elements. A mesh density of 32 x 60 elements was used because this density provided convergence to a final solution. Because the test was to determine performance in torsion, the rotation about the axis of the wall in both models was compared. Table 5 below shows the results of the analysis. The results of the meshed wall model should have matched closely to the line element model, however, they did not.

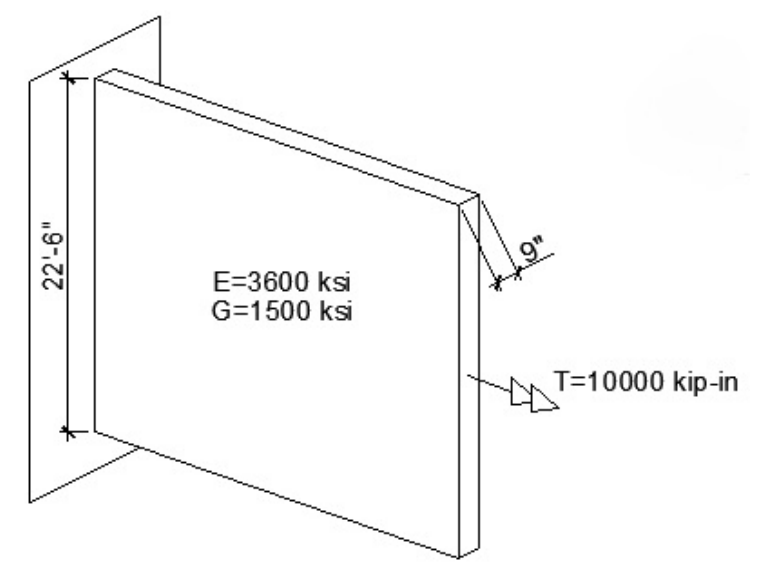

Figure MM: Test Wall for Torsional Stiffness

Table 5: Comparison Between Line and Shell Element Used for Torsion

\begin{tabular}{|c|c|c|c|}
\hline & Line Element Model & Shell Element Model & $\%$ Difference \\
\hline $\begin{array}{c}\text { Rotation about axis of } \\
\text { wall }\end{array}$ & $0.001989 \mathrm{rad}$ & $0.001096 \mathrm{rad}$ & $81.5 \%$ \\
\hline
\end{tabular}

Due to the large difference between the results of the meshed wall model and the theoretically accepted value (the line element model), the shell elements were confirmed to be artificially stiff in torsion.

Determination of the Modal Parameters of a Five Story Reinforced Concrete Structure Using Low Level Excitation and Computational Analysis 
Experimental Basis 51

Due to the inability of the shell elements to accurately model torsion, further development of the line wall element model was pursued. Previously, the line wall element model used disconnected rectangular line elements to construct the various wall assemblages of the structure. Next, a new model was developed that used a single line element to model an entire wall assemblage with properties for moments of inertia, shear areas, and torsional constants manually entered. The section properties of the wall assemblages were obtained from the finite element section analysis software, ShapeDesigner SaaS (MechaTools Technologies 2011).

With the walls properly modeled, the next step was to remove the rigid diaphragm constraints across the floors thereby modeling the stiffness of the diaphragm. However, with the rigid diaphragm constraints removed, attention had to be paid to the points where the walls attached to the diaphragm. Previously this was not an issue because the degrees of freedom across the diaphragm were locked to each other. Since the walls in the line element model only met the diaphragm at a specific point (the geometric centroid of the wall), proper modeling of the wall/diaphragm connection became an issue. To properly model the connection of the walls to the diaphragm, rigid diaphragm constraints were placed to ensure that the translational degrees of freedom of the slab along the cross section of the wall were locked to the degrees of freedom of the point where the line element (centerline of the wall) met the diaphragm. This modeling technique is illustrated in Figure NN on the next page.

Determination of the Modal Parameters of a Five Story Reinforced Concrete Structure Using Low Level Excitation and Computational Analysis 


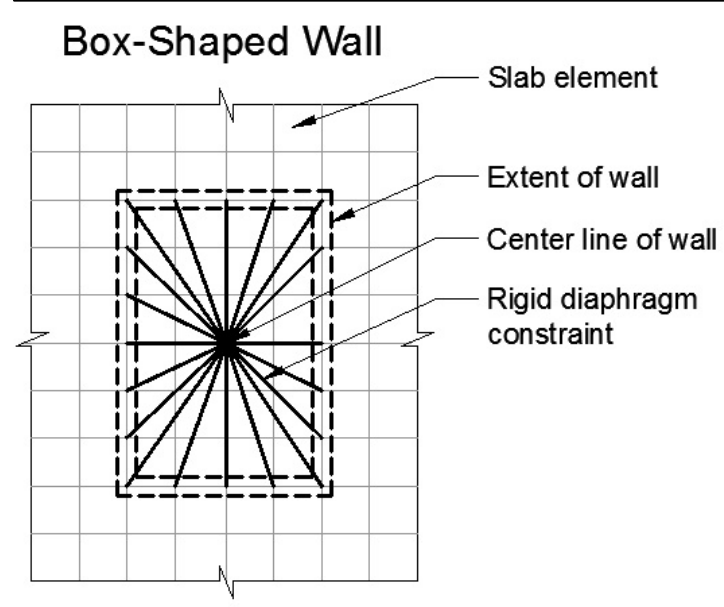

\section{PLAN}

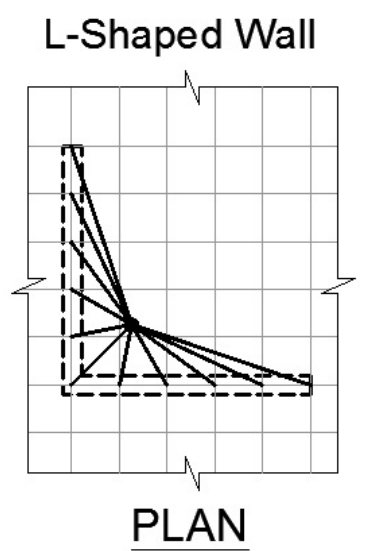

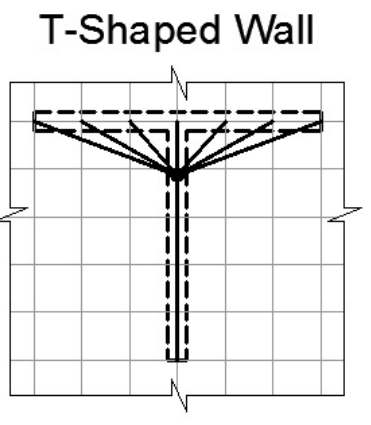

PLAN

\section{Figure NN: Rigid Diaphragm Constraints at Wall/Slab Intersection}

Another consequence of not modeling the diaphragm as rigid is that the mass

could no longer be assigned as point masses at the center of mass. The mass had to now

be modeled as area masses assigned to each slab/shell element. However, modeling the mass as area mass can cause errors in the torsional modes if the mesh of the diaphragm isn't fine enough. Therefore, the relationship between mesh density and the effect on the torsional mode was studied in a series of analyses. Following is a description of the test structure. Table 6 illustrates the results of the analyses.

Description of Structure:

- Single bay, single story

- Story Height: $12^{\prime}$

- Bay size: $13.5^{\prime}$ x $13.5^{\prime}$

- Weight of Story: 1000 kips

- Columns:

○ 6" square steel columns

○ Modulus: $29000 \mathrm{ksi}$

- Shear and torsion of columns neglected

- Rotation restrained about global $\mathrm{x}$ and $\mathrm{y}$ axes to enforce double bending assumption

Determination of the Modal Parameters of a Five Story Reinforced Concrete Structure Using Low Level Excitation and Computational Analysis 

○ Fixed at base
No rigid offsets
○ No self-weights

- Slab

○ 1 " deep membrane elements

○ Rigid "point diaphragm" assigned to all joints

- Additional area mass assigned to all elements

○ No self-weights

The theoretical period of the test structure from Table 6 was determined as follows

(Chopra 2007). Global displacements can be determined from the solution of the free vibration equation of MDF system given in Equation 17 below.

$$
m \ddot{u}+k u=0
$$

Where $m$ is the mass of the system,

$k$ is the stiffness of the system,

$u$ is the displacement of the system, and

$\ddot{u}$ is the acceleration of the system.

The mass and stiffness can be determined by hand for this structure and the displacement can be described in terms of modal coordinates by Equation 18 .

$$
u(t)=q_{n}(t) \phi_{n}
$$

The time variation of displacements can be determined from Equation 19 below

$$
q_{n}(t)=A_{n} \cos \left(\omega_{n} t\right)+B_{n} \sin \left(\omega_{n} t\right)
$$

Plugging both of these equations back into Equation 16 gives

$$
\left(-\omega_{n}^{2} m \phi_{n}+k \phi_{n}\right) q_{n}(t)=0
$$

This equation can be satisfied if $q_{n}(t)=0$. However, this result implies that the system does not move. The alternative is to make the first term of Equation 20 equal to zero and 
solve for $\omega_{n}$ (the natural frequencies) and $\phi_{n}$ (the natural modes). This is shown by equation 21 .

$$
\left(k-\omega_{n}^{2} m\right) \phi_{n}=0
$$

This equation has the solution $\phi_{n}=0$. However, because this solution implies no motion, it is not of interest. Nontrivial solutions exist if the determinant shown in Equation 22 exists

$$
\operatorname{det}\left(k-\omega_{n}^{2} m\right)=0
$$

When Equation 21 is expanded, the result is a polynomial of order N. This polynomial can be solved for $\omega_{n}^{2}$, the natural frequencies of the structure. The natural frequencies can then be plugged into Equation 21 to get their corresponding mode shapes, $\phi_{n}$.

\section{Table 6: Mesh Density vs. Torsional Mode Period}

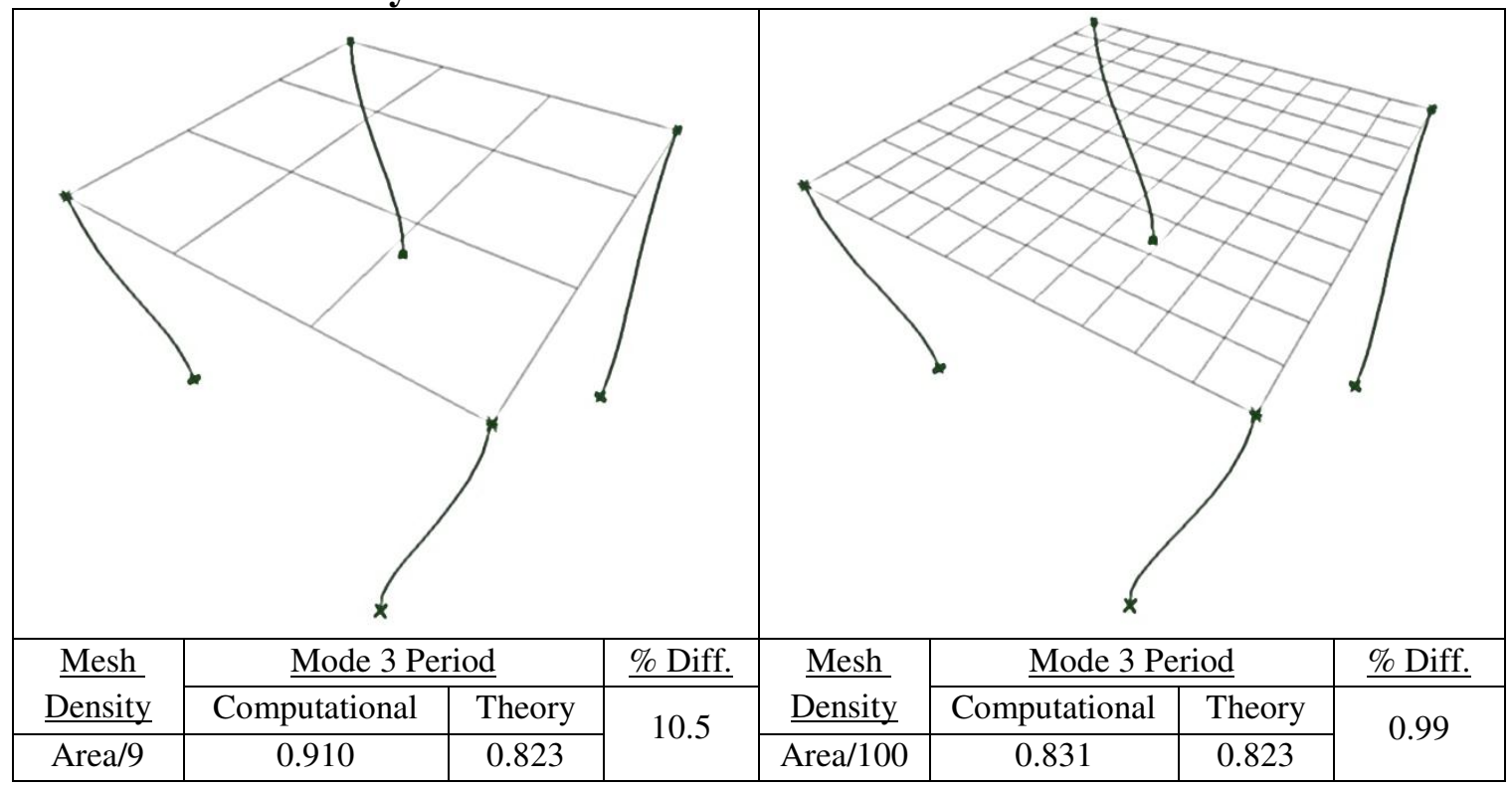

Determination of the Modal Parameters of a Five Story Reinforced Concrete Structure Using Low Level Excitation and Computational Analysis 
The same mesh density that was used in the test structure to get to within $1 \%$ of the theoretical period for the torsional mode (about 2' by $2^{\prime}$ square elements) was used in the current model.

The analysis was then run with the previously described modifications:

- A fine diaphragm mesh

- Walls modeled as wall assemblages, and

- Rigid constraints placed at the wall/slab intersection.

This model is shown in Figure OO. A comparison between the natural frequencies of the line wall element model and the experimental natural frequencies are presented in

\section{Table 7.}

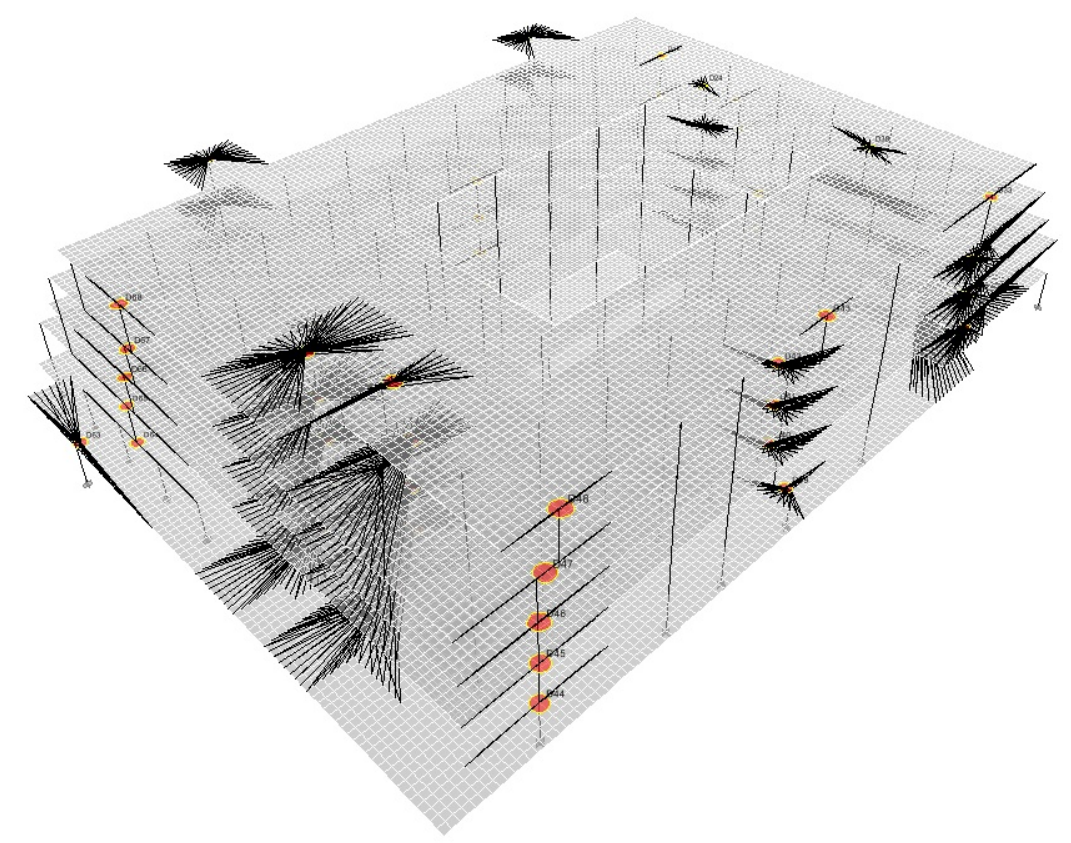

Figure OO: Line Element Model

Determination of the Modal Parameters of a Five Story Reinforced Concrete Structure Using Low Level Excitation and Computational Analysis 
Table 7: Line Wall Element Model vs. Experimental Results

\begin{tabular}{|c|c|c|c|}
\hline & Mode 1 $(\mathrm{Hz})$ & Mode 2 $(\mathrm{Hz})$ & Mode 3 $(\mathrm{Hz})$ \\
\hline Model Frequency & 3.969 & 4.446 & 5.828 \\
\hline $\begin{array}{c}\text { Experimental } \\
\text { Frequency }\end{array}$ & 3.300 & 3.650 & 4.560 \\
\hline \% Difference & $16.8 \%$ & $17.9 \%$ & $18.4 \%$ \\
\hline
\end{tabular}

Table 7 shows that the difference between the experimental natural frequencies and those obtained from the line wall element model are less than $20 \%$. It would take a significant amount of additional mass (about 12" of concrete across the entire diaphragm at each floor) in the analytical model to lower the modal frequencies to within about $10 \%$ of the experimental results.

However, there remains important behavior that has not yet been accounted for in this model. This behavior is the effect of concrete cracking that occurs as the concrete cures and ages. Concrete cracking in the shear walls has the effect of reducing the initial stiffness of each wall. In order to account for cracked concrete, a reduced stiffness was used for the walls. An effective stiffness of $0.7 I_{g} E_{c}$ was used for each wall (ACI 2008);

where $I_{g}$ is the gross moment of inertia of the wall and $E_{c}$ is Young's modulus for concrete ( $\left.E_{c}=3605 \mathrm{ksi}\right)$. A comparison between the natural frequencies determined experimentally and those of the line wall element model with a reduced effective stiffness are presented in Table 8 .

Determination of the Modal Parameters of a Five Story Reinforced Concrete Structure Using Low Level Excitation and Computational Analysis 
Table 8: Experimental Results vs. Cracked Line Wall Element Model

\begin{tabular}{|c|c|c|c|}
\hline & Mode 1 $(\mathrm{Hz})$ & Mode 2 $(\mathrm{Hz})$ & Mode 3 $(\mathrm{Hz})$ \\
\hline Model Frequency & 3.539 & 4.049 & 5.163 \\
\hline $\begin{array}{c}\text { Experimental } \\
\text { Frequency }\end{array}$ & 3.300 & 3.650 & 4.560 \\
\hline \% Difference & $6.7 \%$ & $9.8 \%$ & $11.6 \%$ \\
\hline
\end{tabular}

These results show a close correlation between the experimental and analytical results. Given the estimation of the effective live load, a $10 \%$ difference in natural frequencies is reasonable. In order to understand what a $10 \%$ difference in natural frequencies amounts to, two additional analyses were run. The first one included an additional 3" of 150 pcf concrete across each floor. Three inches of normal weight concrete amounts to about $14 \%$ of the estimated floor weight. The results are shown in Table 9 on the next page. The second analysis reduced the stiffness of the walls to $60 \%$ of the gross stiffness. Since using $70 \%$ of the gross stiffness of the shear walls is a suggestion in ACI 318 based on experimental data, a reduction was explored here to study the sensitivity of the results to this value. The results are presented in Table 10 .

Table 9: Exp. Results vs. Cracked Line Wall Element Model (Additional 3" Concrete)

\begin{tabular}{|c|c|c|c|}
\hline & Mode 1 (Hz) & Mode 2 $(\mathrm{Hz})$ & Mode 3 (Hz) \\
\hline Model Frequency & 3.165 & 3.640 & 4.643 \\
\hline $\begin{array}{c}\text { Experimental } \\
\text { Frequency }\end{array}$ & 3.300 & 3.650 & 4.560 \\
\hline \% Difference & $4.3 \%$ & $0.3 \%$ & $1.8 \%$ \\
\hline
\end{tabular}

Table 10: Exp. Results vs. Cracked Line Wall Element Model (60\% Gross Stiffness)

\begin{tabular}{|c|c|c|c|}
\hline & Mode 1 $(\mathrm{Hz})$ & Mode 2 $(\mathrm{Hz})$ & Mode 3 $(\mathrm{Hz})$ \\
\hline Model Frequency & 3.393 & 3.905 & 5.013 \\
\hline $\begin{array}{c}\text { Experimental } \\
\text { Frequency }\end{array}$ & 3.300 & 3.650 & 4.560 \\
\hline \% Difference & $2.8 \%$ & $6.9 \%$ & $9.9 \%$ \\
\hline
\end{tabular}

Determination of the Modal Parameters of a Five Story Reinforced Concrete Structure Using Low Level Excitation and Computational Analysis 
Experimental Basis 58

Since the line element wall model was made using assumptions for stiffness and mass, the analyses summarized in Tables 9 and 10 explore the effects of slight variations in these analysis properties. The results in these tables suggest that the mass of the building was likely underestimated since adding mass rather than reducing stiffness resulted in better correlation between the experimental natural frequencies and those from the analysis model.

For comparative purposes, the meshed wall model with the same slab characteristics as the line element wall model was run next. This model is shown in Figure PP below. A comparison between the natural frequencies of the meshed wall model and the experimental natural frequencies are presented in Table 11. This model has not yet been modified for concrete cracking.

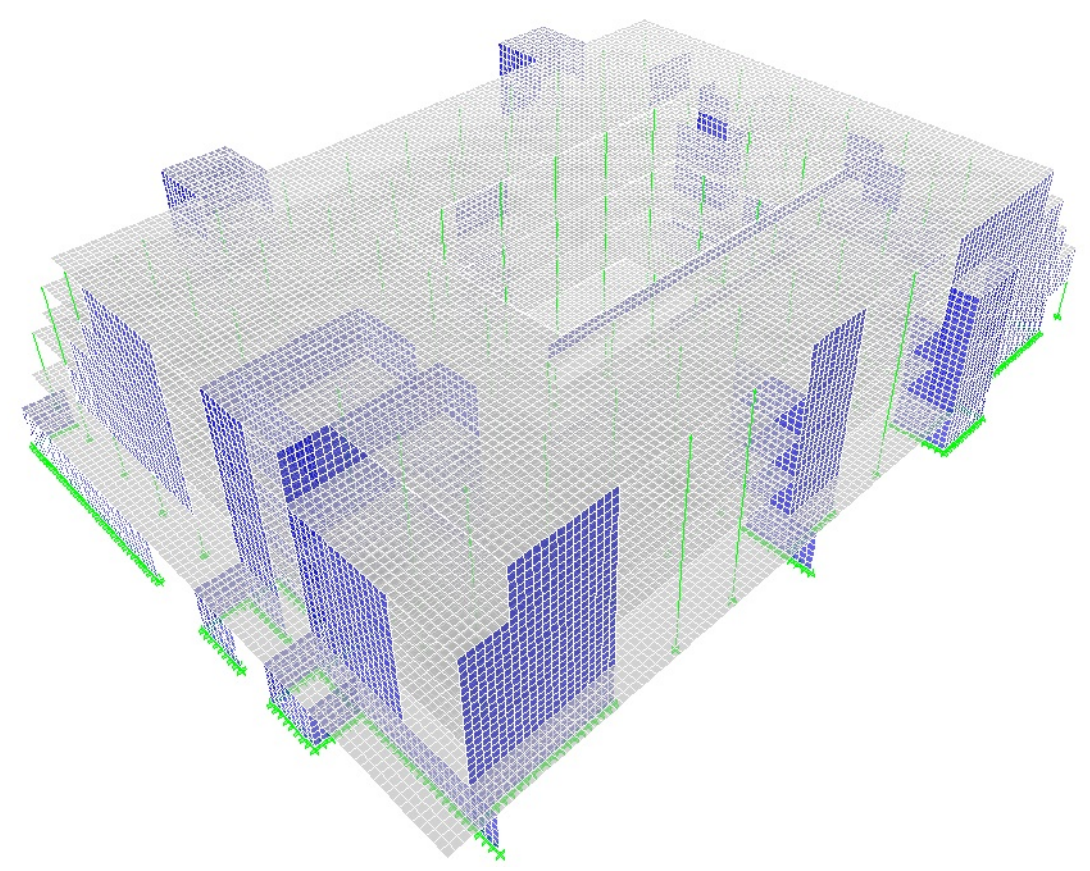

Figure PP: Meshed Wall Model

Determination of the Modal Parameters of a Five Story Reinforced Concrete Structure Using Low Level Excitation and Computational Analysis 
Table 11: Meshed Wall Model vs. Experimental Results

\begin{tabular}{|c|c|c|c|}
\hline & Mode 1 $(\mathrm{Hz})$ & Mode 2 $(\mathrm{Hz})$ & Mode 3 $(\mathrm{Hz})$ \\
\hline Model Frequency & 3.954 & 4.480 & 5.981 \\
\hline $\begin{array}{c}\text { Experimental } \\
\text { Frequency }\end{array}$ & 3.300 & 3.650 & 4.560 \\
\hline \% Difference & $16.5 \%$ & $18.3 \%$ & $23.7 \%$ \\
\hline
\end{tabular}

Table 11 shows that the meshed wall model produces results similar to the line element wall model results (table 7) for the first two modes, but is too stiff in the third/torsional mode. These results were expected based on the previous study which proved the shell elements inadequate to model torsion.

As was done in the line element wall model to account for cracked concrete, a reduced stiffness was used for the meshed walls. As before, an effective stiffness of $70 \%$ of the gross stiffness was used in a separate analysis. A comparison between the natural frequencies determined experimentally and those of the meshed wall model with a reduced effective stiffness is presented in Table 12 below.

Table 12: Experimental Results vs. Cracked Meshed Wall Model

\begin{tabular}{|c|c|c|c|}
\hline & Mode 1 (Hz) & Mode 2 (Hz) & Mode 3 (Hz) \\
\hline Model Frequency & 3.425 & 3.880 & 5.207 \\
\hline $\begin{array}{c}\text { Experimental } \\
\text { Frequency }\end{array}$ & 3.300 & 3.650 & 4.560 \\
\hline \% Difference & $3.6 \%$ & $5.9 \%$ & $12.4 \%$ \\
\hline
\end{tabular}

Table 12 shows that the natural frequencies from the meshed wall model modified for concrete cracking matched the experimentally determined natural frequencies better than the line element wall model for the first two modes (Table 8). These results are unexpected given that the line element wall model produced better results than the

Determination of the Modal Parameters of a Five Story Reinforced Concrete Structure Using Low Level Excitation and Computational Analysis 
Experimental Basis 60

meshed wall model to begin with (compare Tables 7 and 11). However, it was discovered that these results were adversely affected by the stiffness modifiers used in the meshed wall model. The meshed wall model modifies the flexural stiffness by reducing the thickness of each element. In turn, the shear area is also being reduced which results in a section that is too flexible. This effect explains why Table 12 shows such close correlation.

A summary of all the models and their resulting natural frequencies is presented in Table 13 on the next page. 
Experimental Basis 61

Table 13: Summary of Computational Models

\begin{tabular}{|c|c|c|c|}
\hline Model Assumptions & Mode $1(\mathrm{~Hz})$ & Mode $2(\mathrm{~Hz})$ & Mode $3(\mathrm{~Hz})$ \\
\hline $\begin{array}{l}\text { - Walls modeled as disconnected } \\
\text { rectangular line elements } \\
\text { - Double Bending } \\
\text { - Neglect shear and torsional stiffness } \\
\text { - Neglect out-of-plane stiffness } \\
\text { - Rigid diaphragm assumption }\end{array}$ & 20.08 & 33.00 & 51.28 \\
\hline $\begin{array}{l}\text { - All previous assumptions } \\
\text { - Include shear stiffness }\end{array}$ & 5.45 & 6.57 & 7.97 \\
\hline $\begin{array}{l}\text { - All previous assumptions } \\
\text { - Include torsional and out-of-plane } \\
\text { stiffness }\end{array}$ & 5.46 & 6.57 & 7.97 \\
\hline $\begin{array}{l}\text { - All previous assumptions } \\
\text { - No double bending }\end{array}$ & 2.56 & 3.64 & 4.92 \\
\hline $\begin{array}{l}\text { - All previous assumptions } \\
\text { - Rigid constraints to enforce plane } \\
\text { sections remaining plane at wall/slab } \\
\text { intersection }\end{array}$ & 2.87 & 3.90 & 5.11 \\
\hline $\begin{array}{l}\text { - All previous assumptions } \\
\text { - Mesh walls to model wall assemblages } \\
\text { (different cross sections) }\end{array}$ & 3.65 & 4.85 & 5.94 \\
\hline $\begin{array}{l}\text { - All previous assumptions } \\
\text { - Walls modeled as line elements } \\
\text { representing entire assemblage } \\
\text { - Include torsional constraints } \\
\text { - Semi-rigid diaphragm }\end{array}$ & 3.97 & 4.45 & 5.83 \\
\hline $\begin{array}{l}\text { - All previous assumptions } \\
\text { - Account for concrete cracking }\end{array}$ & 3.54 & 4.05 & 5.16 \\
\hline $\begin{array}{l}\text { - All previous assumptions } \\
\text { - Walls modeled as meshed shell elements }\end{array}$ & 3.95 & 4.48 & 5.98 \\
\hline $\begin{array}{l}\text { - All previous assumptions } \\
\text { - Account for concrete cracking }\end{array}$ & 3.43 & 3.89 & 5.21 \\
\hline Experimental Data & 3.300 & 3.650 & 4.560 \\
\hline
\end{tabular}

Determination of the Modal Parameters of a Five Story Reinforced Concrete Structure Using Low Level Excitation and Computational Analysis 
Experimental Basis 62

\subsection{Comparison of Analytical to Experimental Mode Shapes}

Due to the inability to effectively model concrete cracking and torsional stiffness, the meshed wall model was not compared with the experimental mode shapes; only the line element wall model was used for this purpose. The formula used for the comparison was the mass weighted MAC number presented in section 2.7. Table 14 below shows the mass weighted MAC numbers that compare both the apparent (non-swept) mode shapes (AMS) and the final experimental mode shapes (EMS) to the mode shapes from the line wall element model.

Table 14: MAC Numbers Comparing the Line Element Model Mode Shapes with the Apparent Mode Shapes (AMS) and Experimental Mode Shapes (EMS)

\begin{tabular}{|c|c|c|c|}
\hline & Mode 1 & Mode 2 & Mode 3 \\
\hline AMS (non-swept) & 0.772 & 0.866 & 0.176 \\
\hline EMS (Pure Mode 2) & 0.726 & 0.866 & 0.831 \\
\hline
\end{tabular}

Table 14 highlights the fact that the MAC number for mode 1 actually gets worse when EMS 2 is swept from AMS 1 and 3. The MAC number gets worse because EMS 2 isn't actually pure; there is some of mode 1 in EMS 2, and when it is swept out of AMS 1, some of mode 1 is actually being taken out. Also, by comparing EMS 3 with analytical mode 3, there is a significant improvement because EMS 1 and 2 are swept out of AMS 3. Sweeping in this order corrects the discrepancy noted earlier where mode 1 was inexplicably present in AMS 3. Also, the fact that the MAC number for mode 1 is only 0.726 suggests that experimental mode 1 isn't as accurate as it could be and that better shaker locations may exist that can better isolate the mode shapes. The proposed shaker locations are shown in Figure FF.

Determination of the Modal Parameters of a Five Story Reinforced Concrete Structure Using Low Level Excitation and Computational Analysis 
Experimental Basis 63

\subsection{Modeling Conclusions}

Analytical modeling of building dynamic behavior is an iterative process. Models should start simple so that results can be checked against known results. Then changes to the base model should only be made based on the understanding of modeling assumptions, structural behavior, and analytical theory.

Models that could be easily analyzed by hand were the first explored in modeling the Kennedy Library. They consisted of modeling the building with line elements forced into double bending by an infinitely rigid slab. The first model neglected shear deformation, out of plane stiffness, and torsional stiffness and treated all the walls as disconnected rectangular sections. It also treated the slab as rigid and the mass was assigned as point masses at the center of mass. This analysis resulted in a fundamental frequency of $20.1 \mathrm{~Hz}$, far larger than the experimental fundamental frequency of $3.3 \mathrm{~Hz}$. The next hand analysis left everything constant from the first model and added shear deformation. This analysis resulted in a fundamental frequency of $5.45 \mathrm{~Hz}$. Such a dramatic difference shows the significance of accounting for shear deformation. Even with walls that have an average aspect ratio of 2 , the shear deformation can be as high as 40 percent of the total deformation (assuming elastic behavior).

The next models were all done using computer software. Once the computational model was validated using the $2^{\text {nd }}$ hand analysis, out-of-plane wall stiffness and torsional stiffness was included. These changes raised the fundamental frequency to $5.46 \mathrm{~Hz}$. Removing the rotational constraints at the ends of each wall (removing the double bending assumption) and using an equivalent thickness to model the waffle slab dropped

Determination of the Modal Parameters of a Five Story Reinforced Concrete Structure Using Low Level Excitation and Computational Analysis 
Experimental Basis 64

the fundamental frequency from $5.46 \mathrm{~Hz}$ to $2.56 \mathrm{~Hz}$. Adding a rigid constraint (in the plane of the wall bending) ensured deformation compatibility at the wall/slab intersection and resulted in a fundamental frequency of $2.87 \mathrm{~Hz}$.

In order to address the larger moment of inertia and torsional constant that arises from wall assemblages such as T-sections, L-sections and box sections, a new model was made that explicitly modeled wall geometry. This model, which utilized shell elements to model the walls, resulted in a fundamental frequency of $3.65 \mathrm{~Hz}$. However, once it was shown that shell elements were unable to accurately model torsion, this meshed wall model was kept only to be compared with the line element wall model. Therefore, the line element wall model was further developed.

To address the issue of wall assemblages in the line element wall model, each wall was defined at its centroid by a single line element with all the properties of the wall's cross section. To model the flexibility observed in the experimental third mode, the entire diaphragm could no longer be modeled as rigid. Removing the rigid constraints led to rigid diaphragm constraints having to be placed so that the translational degrees of freedom of the slab along the cross section of the wall were locked with the point where the line element (centerline of the wall) met the diaphragm. Also, without the rigid diaphragm constraints assigned across each floor, the point masses defined at the center of mass had to be changed to area masses assigned to each element on the diaphragm. In order to accurately model the mass moment of inertia, a dense mesh (about 2' by 2'

Determination of the Modal Parameters of a Five Story Reinforced Concrete Structure Using Low Level Excitation and Computational Analysis 
Experimental Basis 65

square elements) had to be used. This model changed the fundamental frequency of the previous line element wall model of $2.87 \mathrm{~Hz}$ to $3.97 \mathrm{~Hz}$.

Comparing the line element wall model to the meshed wall model showed similar results for the first two frequencies, but as expected, the meshed wall model was not as accurate in predicting the torsional third mode. The final change to the two models was a modification for concrete cracking. Seventy percent of the gross stiffness for bending was used and the analysis resulted in the final analytical fundamental frequency of $3.54 \mathrm{~Hz}$ for the line element wall model (within $7 \%$ of the experimental frequency) and $3.43 \mathrm{~Hz}$ for the meshed wall model (within $4 \%$ of the experimental frequency). However, the method used for modifying the flexural stiffness of the walls in the meshed wall model had the effect of also reducing the shear stiffness, making the model too flexible in shear. For this reason, and because the shell elements were artificially stiff in torsion, only the line element wall model was used for comparing mode shapes.

The line element model mode shapes were compared with the experimentally derived mode shapes; mass weighted MAC numbers of $0.726,0.866$, and 0.831 were calculated for the first, second, and third modes, respectively. The poor correlation of 0.726 for the first mode suggests that mode 1 may not have been experimentally captured as well as it could have been, and further investigation could be done. For this reason, additional shaker may exist that could better isolate the three mode shapes. If after further investigation, it is determined that the first mode was captured correctly, further refinement of the computational model would be necessary.

Determination of the Modal Parameters of a Five Story Reinforced Concrete Structure Using Low Level Excitation and Computational Analysis 
Experimental Basis 66

\subsection{CONCLUSIONS}

Ultra-Low Forced Vibration Testing (UL-FVT), as described in this paper, can generate detectable accelerations throughout a building as massive as the Kennedy Library. Accelerations induced by the shaker were recorded as high as $60 \mu \mathrm{g}$, about 12 times the average ambient acceleration readings. Induced accelerations were detected across the entire diaphragm at the $5^{\text {th }}, 4^{\text {th }}$, and $3^{\text {rd }}$ floors, with the shaker operating at the $5^{\text {th }}$ floor.

Ambient Vibration Tests (AVT) and Forced Vibration Tests (FVT) were performed to find both the first three natural frequencies of the building and the shaker locations/orientations to isolate each mode. Mode shape mapping was then used to determine the shape of deformation induced by the shaker oscillating at each location at its respective frequency. Mode shape mapping resulted in what was referred to as Apparent Mode Shapes (AMS). Apparent Mode Shapes are derived from the measured (global) accelerations. Every mode contributes to an Apparent Mode Shape, with the target mode having the most influence. To obtain the final Experimental Mode Shapes (EMS), the Modified Gram-Schmidt (MGS) was used to sweep out the influence of the other modes from the target AMS.

Once the Apparent Mode Shapes were determined, mass-weighted MAC numbers were calculated to determine the orthogonality of the shapes to each other (see Table 2). The MAC numbers were used to determine that AMS 2 was the most "pure" of the three Apparent Mode Shapes, and was therefore referred to as Experimental Mode Shape 2 (EMS 2). EMS 2 was swept out of AMS 1 to produce EMS 1. EMS 1 and EMS 2 were 
Experimental Basis 67

then swept out of AMS 3 to produce EMS 3. The MAC numbers also revealed that there was a large amount of AMS 1 in AMS 3. This result was unexpected and led to the consideration of future work. Future work that may result in more accurate AMS's and EMS's include: exploring new shaker locations, describing the mode shapes with more degrees of freedom, and exploring the influence of higher modes.

Models that could be easily analyzed by hand were the first explored in modeling the Kennedy Library. They consisted of modeling the building with line elements forced into double bending by an infinitely rigid slab. The first model neglected shear deformation, out of plane stiffness, and torsional stiffness and treated all the walls as disconnected rectangular sections. It also treated the slab as rigid and the mass was assigned as point masses at the center of mass.

The next models were all done using computer software. Out-of-plane wall stiffness and torsional stiffness was added to the model but found not to produce significant differences. The next step was to remove the rotational constraints at the ends of each wall (removing the double bending assumption) and use an equivalent thickness to model the waffle slab. Also, rigid constraints were added at the wall/slab intersection (rigid in the plane of the wall bending) to ensure deformation compatibility at this intersection.

A meshed shell element wall model was also explored in order to explicitly model the wall geometry. However, once it was shown that shell elements were unable to

Determination of the Modal Parameters of a Five Story Reinforced Concrete Structure Using Low Level Excitation and Computational Analysis 
Experimental Basis 68

accurately model torsion, this meshed wall model was kept only to be compared with the line element wall model.

To address the issue of wall assemblages in the line element wall model, each wall was defined at its centroid by a single line element with all the properties of the wall's cross section. To model the flexibility observed in the experimental third mode, the entire diaphragm could no longer be modeled as rigid. Removing the rigid constraints led to rigid diaphragm constraints having to be placed so that the translational degrees of freedom of the slab along the cross section of the wall were locked with the point where the line element (centerline of the wall) met the diaphragm. Also, without the rigid diaphragm constraints assigned across each floor, the point masses defined at the center of mass had to be changed to area masses assigned to each element on the diaphragm. In order to accurately model the mass moment of inertia, a dense mesh (about 2' by 2' square elements) had to be used.

Comparing the line element wall model to the meshed wall model showed similar results for the first two frequencies, but as expected, the meshed wall model was not as accurate in predicting the torsional third mode. The final change to the two models was a modification for concrete cracking. Seventy percent of the gross stiffness for bending was used and the analysis results fell to within $7 \%$ of the experimental frequency for the line element wall model and to within $4 \%$ of the experimental frequency for the meshed wall model. However, because of the discrepancies noted in section 3.0, only the line element wall model was used for comparing mode shapes.

Determination of the Modal Parameters of a Five Story Reinforced Concrete Structure Using Low Level Excitation and Computational Analysis 
Experimental Basis 69

The line element model mode shapes were compared with the experimentally derived mode shapes; mass weighted MAC numbers of $0.726,0.866$, and 0.831 were calculated for the first, second, and third modes, respectively. The poor correlation of 0.726 for the first mode suggests that mode 1 may not have been experimentally captured as well as it could have been, and further investigation could be done. If after further investigation, it is determined that the first mode was captured correctly, further refinement of the computational model would be necessary.

This project focused on model refinement based on comparisons with experimental results. The close correlation between the experimental and computational results prove that by comparing experimentally determined modal parameters with analytically determined modal parameters, analytical models can be refined to more accurately capture important structural dynamic behavior.

Determination of the Modal Parameters of a Five Story Reinforced Concrete Structure Using Low Level Excitation and Computational Analysis 


\subsection{REFERENCES}

(ACI 2008) ACI committee 318. Building Code Requirements for Structural Concrete and Commentary (ACI 318-08). Farmington Hills, Michigan: American Concrete Institute, 2008.

(Allemang 2003) Allemang, R. J. "The Modal Assurance Criterion - Twenty Years of Use and Abuse." Sound and Vibration 37.8 (2003): 14-23.

(ASCE 7-05 2006) The Structural Engineer Institute of the American Society of Civil Engineers. Minimum Design Loads for Buildings and Other Structures. American Society of Civil Engineers, 2006.

(Bradford, et al. 2004) Bradford, S.C., J.F. Clinton, J. Favela, and T.H. Heaton. Results of Millikan Library Forced Vibration Testing. Pasadena, California: California Institute of Technology, Earthquake Engineering Research Laboratory, 2004.

(Celebi et al. 1993) Celebi, M., L.T. Phan, and R.D. Marshall. "Dynamic Characteristics of Five Tall Buildings During Strong and Low-Amplitude Motions." The Structural Design of Tall Buildings 2.1 (1993): 1-15.

(Chakraverty 2005) Chakraverty, S. "Identification of Structural Parameters of Multistory Shear Buildings from Modal Data." Earthquake Engineering and Structural Dynamics 34 (2005): 543-554.

(Chopra 2007) Chopra, A. K. Dynamics of Structures, Theory and Applications to Earthquake Engineering, Third Edition. New Jersey: Pearson Prentice-Hall, 2007.

(CSI 2005) CSI. CSI Analysis Reference Manual. Berkeley, California: Computers \& Structures Inc., 2005.

(Golub and Van Loan 1989) Golub G.H. and Van Loan C.F. Matrix Computations: Second Edition. Baltimore: Johns Hopkins University Press, 1989.

(Hudson 1961) Hudson, D.E. “A New Vibration Exciter For Dynamic Tests of Full-Scale Structures." Pasadena, California: Earthquake Engineering Research Laboratory, California Institute of Technology, 1961.

(Ivanovic and Todorovska 2000a) Ivanovic, S. S., M. D. Trifunac, E. I. Novikova, A. A. Gladkov and M. I. Todorovska. "Ambient Vibration Tests of a Seven-Story Reinforced Concrete Building in Van Nuys, California, Damaged by the 1994 Northridge Earthquake." Soil Dynamics and Earthquake Engineering 19.6 (2000): 391-411. 
(Ivanovic and Todorovska 2000b) Ivanovic, S. S, M. D. Trifunac, M. I. Todorovska. "Ambient Vibration Tests of Structures - A Review." ISET Journal of Earthquake Technology 37.4 (2000): 165-197.

(Jennings, et al. 1971) Jennings, P.C, R.B. Matthiesen, and J. Brent Hoerner. "Forced Vibration of a Tall Steel-Frame Building." Earthquake Engineering and Structural Dynamics 1 (1972): 107-132.

(Kwan 1996) Kwan, A.K.H. "Shear Lag in Shear/Core Walls." Journal of Structural Engineering 132 (1996): 122-129.

(MathWorks 2009) MathWorks Inc. Matlab 7 Getting Started Guide. Natick, MA: The MathWorks Inc., 2009.

(McDaniel and Archer 2009) McDaniel, C.C., Archer, G. Developing a 'Feel' for Structural Behavior. American Society for Engineering Education (ASEE) Annual Conference, 2009.

(McDaniel and Archer 2010a) McDaniel, C.C., and G. C. Archer. Full-scale, Real-time Building Dynamics Laboratory. $9^{\text {th }}$ U.S. National and $10^{\text {th }}$ Canadian Conference on Earthquake Engineering, Earthquake Engineering Research Institute, 2010.

(McDaniel and Archer 2010b) McDaniel, C.C., and G.C. Archer. Improving Student Understanding of Structural Dynamics Using Full-scale, Real-time Excitation of Buildings. American Society for Engineering Education (ASEE) Annual Conference, 2010.

(Paulay and Priestley 1992) Paulay, T., and M.J.N. Priestley. Seismic Design of Reinforced Concrete and Masonry Buildings. New York: Wiley, 1992.

(Trifunac 1972) Trifunac M.D. "Comparisons Between Ambient and Forced Vibration Experiments." Earthquake Engineering and Structural Dynamics 1 (1972): 133 150.

(Wilson 2002) Wilson, Edward L. Three-Dimensional Static and Dynamic Analysis of Structures. Berkeley, California: Computers and Structures Inc., 2005.

(Yu 2005) Yu, E. "Forced Vibration Testing and Analytical Modeling of a Four-Story Reinforced Concrete Frame Building." Diss. Department of Civil Engineering, University of California, Los Angeles, 2005.

(Yu, et al. 2004) Yu, Eunjong, Daniel H. Whang, Ravi Venugopal, Jonathan P. Stewart, and John V. Wallace. Force-Vibration Testing of Buildings using the Linear Shaker Seismic Simulation (LSSS) Testing Method. $13^{\text {th }}$ World Conference on Earthquake Engineering, 1-6 Aug. 2004, Vancouver, B.C., Canada, 2004.

Determination of the Modal Parameters of a Five Story Reinforced Concrete Structure Using Low Level Excitation and Computational Analysis 
(Yu et al. 2008) Yu, Eunjong, Derek Skolnik, Daniel H. Whang, and John. W. Wallace. "Forced Vibration Testing of a Four-Story Reinforced Concrete Building Utilizing the NEES@UCLA Mobile Field Laboratory." Earthquake Spectra 24.4 (2008): 969-995. 